\title{
Medial Auditory Thalamus Is Necessary for Expression of Auditory Trace Eyelid Conditioning
}

\author{
๑Loren C. Hoffmann, ${ }^{1}$ S. James Zara, ${ }^{2}{ }^{-E v a n ~ D . ~ D e L o r d, ~}{ }^{2}$ and ${ }^{\oplus}$ Michael D. Mauk ${ }^{1,2}$ \\ ${ }^{1}$ Center for Learning and Memory, and ${ }^{2}$ Department of Neuroscience, University of Texas at Austin, Austin, Texas 78712
}

\begin{abstract}
Transforming a brief sensory event into a persistent neural response represents a mechanism for linking temporally disparate stimuli together to support learning. The cerebellum requires this type of persistent input during trace conditioning to engage associative plasticity and acquire adaptively timed conditioned responses (CRs). An initial step toward identifying the sites and mechanisms generating and transmitting persistent signals to the cerebellum is to identify the input pathway. The medial auditory thalamic nuclei (MATN) are the necessary and sufficient source of auditory input to the cerebellum for delay conditioning in rodents and a possible input to forebrain sites generating persistent signals. Using pharmacological and computational approaches, we test (1) whether the necessity of MATN during auditory eyelid conditioning is conserved across species, (2) whether the MATN are necessary for the expression of trace eyelid CRs, and if so, (3)whether this relates to the generation of persistent signals. We find that contralateral inactivation of MATN with muscimol largely abolished trace and delay CRs in male rabbits. Residual CRs were decreased in amplitude, but CR timing was unaffected. Results from large-scale cerebellar simulations are consistent with previous experimental demonstrations that silencing only CSduration inputs does not abolish trace CRs, and instead affects their timing. Together, these results suggest that the MATN are a necessary component of both the direct auditory stimulus pathway to the cerebellum and the pathway generating task-essential persistent signals.
\end{abstract}

Key words: cerebellum; computer simulation; forebrain; persistent input; thalamus; trace eyelid conditioning

Significance Statement

Persistent activity is required for working memory-dependent tasks, such as trace conditioning, and represents a mechanism by which sensory information can be used over time for learning and cognition. This neuronal response entails the transformation of a discrete sensory-evoked response into a signal that extends beyond the stimulus event. Understanding the generation and transmission of this stimulus transformation requires identifying the input sources necessary for task-essential persistent signals. We report that the medial auditory thalamic nuclei are required for the expression of auditory trace conditioning and suggest that these nuclei are a component of the pathway-generating persistent signals. Our study provides a foundation for testing circuitlevel mechanisms underlying persistent activity in a cerebellar learning model with identified inputs and well defined behavioral outputs.

\section{Introduction}

The essence of neural processing is transforming inputs into useful output. Identifying and characterizing inputs is therefore a fundamental initial step toward understanding any particular instance of neural processing. How brief neural responses to a sensory input are transformed into persistent responses that last well

\footnotetext{
Received April 18, 2018; revised Aug. 6, 2018; accepted Aug. 9, 2018.

Author contributions: L.C.H. and M.D.M. designed research; L.C.H., S.J.Z., and E.D.D. performed research; L.C.H. analyzed data; L.C.H. and M.D.M. wrote the paper.

This work was supported by National Institutes of Health Grants MH-46904 and MH-74006 to M.D.M., and T32-MH-106454 to L.C.H. We thank Hunter Halverson and Frank Ruisech for contributions.

The authors declare no competing financial interests.

Correspondence should be addressed to Dr. Loren C. Hoffmann, Center for Learning and Memory, University of Texas at Austin, 1 University Station, C7000, Austin, TX 78712. E-mail: hoffmalc@utexas.edu.

DOI:10.1523/JNEUROSCI.1009-18.2018

Copyright $\odot 2018$ the authors $\quad 0270-6474 / 18 / 388831-14 \$ 15.00 / 0$
}

beyond stimulus offset, a process often connected to the substrates of working memory (Fuster and Alexander, 1971; Funahashi et al., 1989; Zhou and Fuster, 1996), is an important example. Numerous instances of task-related persistent activity have been identified (Suzuki et al., 1997; O'Connor et al., 1997; Egorov et al., 2002; Gilmartin and McEchron, 2005; Tahvildari et al., 2007; Dembrow et al., 2010; Navaroli et al., 2012; Siegel et al., 2012; Hattori et al., 2014; Guo et al., 2017). Observing persistent activity in a region does not mean that it was generated there, it could simply reflect upstream persistent inputs. This highlights the fundamental importance of understanding the stimulus pathways that project to the various regions displaying persistent activity, with the ultimate goal of identifying regions that convert stimulus-duration signals into persistent signals.

Trace eyelid conditioning is a task that requires persistent activity and provides an experimentally tractable means to char- 
acterize pathways that convey stimulus information to regions that produce such activity. This learning task requires at least two separate inputs to the cerebellum, one conveying the conditioned stimulus (CS) and one forebrain-related input conveying a persistent signal that is sustained through the trace interval (Kalmbach et al., 2009, 2010). Thus, somewhere in the pathways between the sensory neurons activated by the auditory CS and the brain regions that provide input to the cerebellum, CS-duration activity is converted into the persistent signals that enable cerebellar learning (Ito and Kano, 1982; Kalmbach et al., 2009). We have tested the hypothesis that the medial auditory thalamic nuclei (MATN) are necessary for trace eyelid conditioning and have further explored their involvement in a pathway connecting the activity elicited by auditory CS to task-related persistent activity that is required for this instance of learning.

Several factors make the MATN a strong candidate. In rodents, these nuclei are a necessary portion of the pathway conveying auditory CS information to the cerebellum in delay eyelid conditioning (Halverson and Freeman, 2006; Halverson et al., 2008). Composed of the medial division of the medial geniculate nucleus, posterior intralaminar nucleus, and suprageniculate nucleus, the MATN receive converging inputs from auditory brainstem nuclei and project ipsilaterally to the lateral pontine nucleus, which supplies mossy fiber inputs to the cerebellum (Kawamura, 1975; Steinmetz and Sengelaub, 1992; Winer et al., 1999, 2001; Malmierca et al., 2002; Campolattaro et al., 2007; Halverson and Freeman, 2010a; Halverson et al., 2015). The MATN are also necessary for a variety of auditory-driven tasks (Iwata et al., 1986; Jarrell et al., 1986; Edeline and Weinberger, 1992; McCabe et al., 1993; Poremba and Gabriel, 1997; Maren et al., 2001). Finally, although forebrain cortical structures are generally the focus of work on persistent activity both in vivo and in vitro (Suzuki et al., 1997; Egorov et al., 2002; Gilmartin and McEchron, 2005; Tahvildari et al., 2007; Dembrow et al., 2010; Navaroli et al., 2012; Siegel et al., 2012; Hattori et al., 2014), task-related persistent activity has also been recorded in the MATN (O'Connor et al., 1997).

We tested the effects of MATN blockade on the expression of trace eyelid responses through pharmacological inactivation and compared these results with those from large-scale computer simulations of the cerebellum to assess MATN contributions to pathways required for persistent activity. The behavioral results demonstrated that reversible inactivation of MATN contralateral to the trained eye blocked both trace and delay conditioned responses (CRs). When trace CRs were not fully blocked, their timing was unaffected. Computer simulation results extend previous work showing that silencing persistent inputs blocks trace CRs, while silencing only the CS-duration input to the cerebellum alters the timing of CRs but does not abolish them (Kalmbach et al., 2010). Combined, these findings suggest that the MATN are a necessary component of the pathways that convey auditory CS-duration information to the cerebellum and those that generate auditory-evoked persistent responses that are required for trace eyelid conditioning.

\section{Materials and Methods}

Subjects. Subjects were 26 male New Zealand White rabbits (Oryctolagus cuniculus) supplied by Covance. The animals weighed $2.5-3.5 \mathrm{~kg}$ at the time of surgery, and were individually housed, maintained on a $12 \mathrm{~h}$ light/dark cycle, and fed daily with water ad libitum in their home cages. All procedures involving animals were approved by the University of Texas at Austin Institutional Animal Care and Use Committee and were performed in accordance with the National Institutes of Health guidelines.
Surgery. Each rabbit was preanesthetized with a subcutaneous injection of ketamine $(45 \mathrm{mg} / \mathrm{kg})$ and acepromazine $(1.5 \mathrm{mg} / \mathrm{kg})$ and mounted on a custom stereotaxic holder (with bregma oriented $1.5 \mathrm{~mm}$ dorsal to lambda). Surgical depth was maintained with 2-3\% isoflurane mixed in oxygen. A custom 23-gauge guide cannula targeted the right medial division of the medial geniculate nucleus at $7.5 \mathrm{~mm}$ posterior to bregma, $5.1 \mathrm{~mm}$ lateral to midline, and $10.5 \mathrm{~mm}$ ventral to brain surface (Fig. 1; see Fig. 3A). This location represented an approximate centering of the cannula within the dorsal-ventral (DV) and anterior-posterior (AP) span of the MATN. A medial-lateral (ML) location targeted just medial to MATN to reduce the spread of muscimol to laterally adjacent nuclei. A 30-gauge stylet extending $1.0 \mathrm{~mm}$ from the end of the guide cannula was inserted to prevent cannula blockage and infection. Each rabbit was also prepared with two stainless steel periorbital stimulating electrodes implanted subdermally to contact the orbital region of the orbicularis oculi, rostral and caudal to the upper eyelid on the side contralateral to the MATN infusion guide cannula. Stimulating wires were fixed to a plug that allowed for connection with the eyelid detector and stimulation leads during training. Guide cannula, skull screws, and detector port were secured to the skull with dental acrylic (catalog \#0921393, Bosworth), and the surgical site was sutured around the acrylic headstage. Carprofen $(4 \mathrm{mg} / \mathrm{kg}, 2 \mathrm{~d})$ and Baytril $(10 \mathrm{mg} / \mathrm{kg}, 1 \mathrm{~d})$ were administered beginning on the first postoperative day. Postoperative recovery was a minimum of $7 \mathrm{~d}$.

Conditioning procedure. Conditioning and infusion procedures were conducted in well ventilated, sound-attenuating chambers $(89 \times 64 \times 49$ $\mathrm{cm})$. Within the conditioning chamber, rabbits were gently restrained in custom Plexiglas restrainers with ears taped to a foam pad to limit head movement. Daily training sessions consisted of 12 blocks of 9 trials (108 trials/session, lasting 60-120 min). Each block began with a CS-alone probe trial followed by eight paired trials, in which a CS and an unconditioned stimulus (US) were presented. Intertrial intervals were selected randomly from a flat distribution ranging from 20 to $40 \mathrm{~s}$. Stimulus delivery and eyelid position data collection were controlled by custom software. The CS was a $1-\mathrm{kHz}$ (trace) or $9.5-\mathrm{kHz}$ (delay) $85-\mathrm{dB}$ pure tone with onset/offset rise/fall times of $5 \mathrm{~ms}$ to avoid onset and offset transients (clicks). Each chamber was equipped with a speaker that was connected to a stereo equalizer and receiver, which received computergenerated input to produce the tone CS. The US was a 50-ms periorbital stimulation (constant current, $100 \mathrm{~Hz}$; pulse width, $1 \mathrm{~ms}$ ) delivered via an isolated pulse stimulator (model 2100, A-M Systems) to two subdermal wires. To record external eyelid position, an infrared emitter/detector was attached to the headstage of each rabbit and aligned with the center of the left eye. The infrared emitter/detector measured upper eyelid position by converting the amount of emitted infrared light reflected to the detector, which increases as the eyelid closes, to a voltage (Medina et al., 2000; Kalmbach et al., 2009). The signal was amplified to yield a signal that was linearly related to upper eyelid position $( \pm 0.1 \mathrm{~mm})$. Before each training session, the US intensity was adjusted for each rabbit to just above the threshold for full eyelid closure (1.5-3.5 mA, depending on the condition of the implanted wires), and the eyelid detector was calibrated by measuring the voltage response produced by a full eyelid closure and defining that voltage change as $6.0 \mathrm{~mm}$ (the amplitude of a maximal eyelid closure in rabbit; Fig. $2 A$ ). During training, external eyelid position was measured for $2.5 \mathrm{~s}$ beginning $200 \mathrm{~ms}$ before the tone onset of each trial. Eyelid responses recorded during training trials were digitized at $1 \mathrm{kHz}$ and stored for subsequent off-line analyses.

A schematic of the two training paradigms used in the present study is shown in Figure $2 A$. For trace eyelid conditioning, each trial consisted of a 500-ms CS and a 50-ms US that were separated by a 500-ms stimulusfree period (the trace interval). For delay eyelid conditioning, a $550-\mathrm{ms}$ CS overlapped and coterminated with the $50-\mathrm{ms}$ US. A CR was defined as an eyelid closure that exceeded $0.3 \mathrm{~mm}$ between CS and US onsets (Fig. $2 A$ ). Trials with eyelid responses $\geq 0.3 \mathrm{~mm}$ in the $200 \mathrm{~ms}$ before CS onset were excluded from behavioral analyses (five or fewer trials per session).

Muscimol infusions. Animals were trained until performance was stable with at least $75 \%$ CRs per session. Subsequent infusion sessions consisted of three preinfusion blocks followed by an infusion of muscimol, a selective $\mathrm{GABA}_{\mathrm{A}}$ receptor agonist, or of ACSF vehicle (counterbalanced). 
A

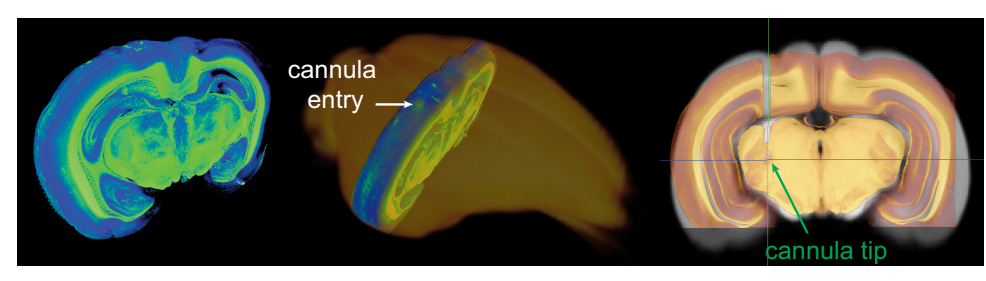

C

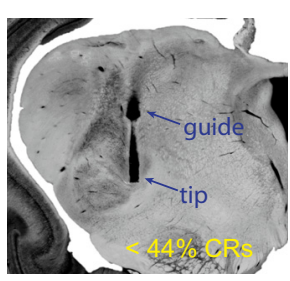

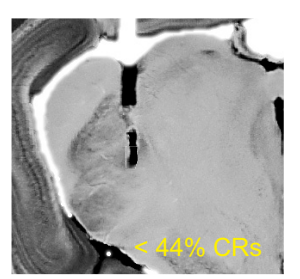

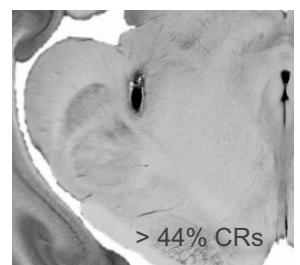

B

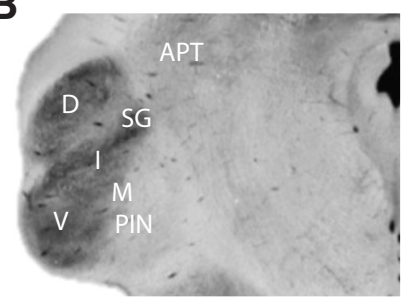

D

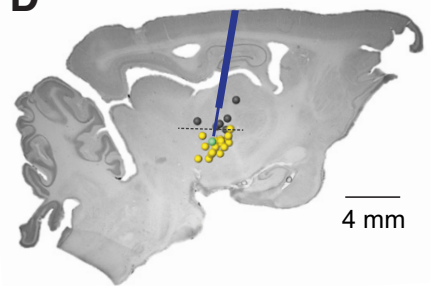

E

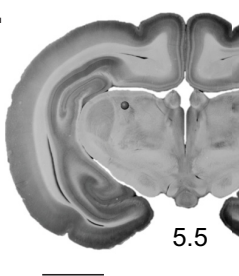

$5 \mathrm{~mm}$

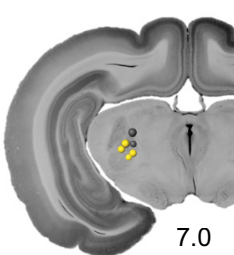

7.0

- Max Effec(3.7\% CRs)

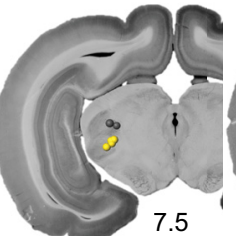

7.5

$0<44 \%$ CRs
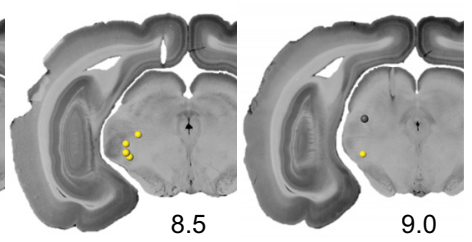

- $>44 \%$ CRs

Figure 1. A, Three-dimensional representation of reconstructed cannula entry cannula tips from serial sections referenced against an MRI standard. $\boldsymbol{B}$, MATN subnuclei, including medial division of medial geniculate nuclei (M), suprageniculate nucleus (SG), and posterior intralaminar nucleus (PIN). The internal (I) division of the medial geniculate nuclei has also been included as previous rabbit studies have anatomically distinguished it from adjacent subregions (Caballero-Bleda et al., 1991; de Venecia et al., 1995) or have implicated this region in behavioral effects under the label of PIN (Poremba and Gabriel, 1997). Dorsal (D) and ventral (V) divisions of medial geniculate nuclei and anterior pretectal nucleus (APT) are shown for reference. C, Example histologies showing cannula placements and corresponding performance-based grouping for three animals. $\boldsymbol{D}, \boldsymbol{E}$, Summary of cannula placements based on digital slice reconstruction, where green dots indicate cannula placement that yielded the maximum postinfusion behavioral effect on trace (Rs, yellow dots show placements with strong behavioral effects ( $<44 \%$ post-infusion (Rs), and gray dots indicate placements 1978 with weak effects ( $>44 \%$ post-infusion (Rs). D , Parasagittal representation shows the distribution of cannula placements (section taken at $4.5 \mathrm{~mm}$ lateral to midline). The dotted horizontal line indicates $9 \mathrm{~mm}$ ventral to brain surface. The average cannula trajectory angle is illustrated in blue. $\boldsymbol{E}$, Serial coronal sections summarizing cannula placements.

After infusion, an additional nine postinfusion training blocks were presented. Before each infusion session, the stylet was removed from the guide cannula and replaced with a 30 -gauge infusion cannula that extended $2.0-3.5 \mathrm{~mm}$ beyond the guide cannula. The infusion cannula was connected to polyethylene tubing (PE 10;25-35 cm; Warner Instruments), which was connected to a $10-\mu$ l Gastight Syringe (model $1701 \mathrm{~N}$; Hamilton). The syringe was placed in an infusion pump (model MD1020, Bioanalytical Systems), and $1.0 \mu \mathrm{l}$ of muscimol, $1.0 \mathrm{~mm}, \mathrm{pH} 7.4$, dissolved in ACSF, or ASCF vehicle (as follows, in mM: $\mathrm{NaCl} 119, \mathrm{KCl} 2.5$, $\mathrm{NaH}_{2} \mathrm{PO}_{4} 1.2, \mathrm{MgCl}_{2} 2, \mathrm{CaCl}_{2} 2, \mathrm{NaHCO}_{3} 26$, D-glucose 10, and HEPES $20, \mathrm{pH} 7.35-7.4$ ) was infused over $10 \mathrm{~min}$ at a rate of $0.1 \mu \mathrm{l} / \mathrm{min}$. The infusion cannula was left in place for the duration of the session and was replaced by the stylet following the session. Each infusion session resumed $27 \pm 12 \mathrm{~min}$ following the end of the infusion period. A subset of the animals with effective infusions during trace conditioning ( $\mathrm{a}>50 \%$ decrease in CR likelihood maintained over training blocks) were used for the delay conditioning infusion phase using the previously verified infusions locations - a detail that is reflected in the strength of the delay infusion behavioral effect.

Histological analyses. After all testing was complete, injection cannulae were inserted and left in place through the perfusion and subsequent fixation periods, which created clear impressions of cannula tracks and injector tips in the tissue (Fig. 1C). Cresyl Violet infusions (FD NeuroTechnologies) were also used in some cases as a secondary visual aid to mark infusion location. Due to differences in composition and molecular weight between this compound and muscimol, we did not use Cresyl Violet infusions as a method for estimating muscimol spread. Animals were killed with an overdose of sodium pentobarbital and were transcardially perfused with $0.9 \%$ physiological saline and $10 \%$ formalin. Brains were removed, embedded in gelatin, frozen, and sectioned on a mi- crotome at $80 \mu \mathrm{m}$. Sections were wet-mount imaged with a stereoscope (SteREO Discovery version 8, Zeiss). Using AMIRA software (version 6.0 , Visage Imaging), a three-dimensional (3-D) reconstruction was created from serial sections for each animal (Fig. 1A). These reconstructions were scaled and overlaid to form a composite that was mapped onto a custom atlas adapted from the Girgis and Wang (1981) stereotaxic atlas and MRI (Fig. 1D,E). One rabbit was excluded from analyses due to cannula movement caused by detachment of the guide cannula from acrylic; however, no animals were excluded based on cannula placement or behavioral effects.

Experimental design and statistical analysis. To determine the effects of muscimol or ACSF infusions on conditioned responding, we compared infusion data with those taken from the previous, noninfusion, day of training. For equivalent periods of comparison, session data were separated into preinfusion (blocks 1-3) and postinfusion (blocks 4-12) phases for each of the three session types (Fig. 2C). CR likelihood refers to the fraction of trials where the response satisfied the $0.3-\mathrm{mm}$ threshold criterion for CR (the number of CR trials divided by the total number of valid trials). For CR likelihood analyses, repeated-measures ANOVAs were used to test for within- and between-subject differences in complete delay and trace datasets, collapsed across cannula depth. Preplanned $t$ tests were then conducted. The amplitude of the CR was defined as the peak eyelid closure between CS onset and US onset. Kolmogorov-Smirnov tests were used to determine differences in CR amplitude distributions during infusion and control sessions (Fig. 2E). A paired $t$-test of average $\mathrm{CR}$ amplitudes during muscimol infusion period assessed delay versus trace differences in the subset used in both experiments. A Pearson's correlation (Fig. 3C) of CR likelihood during MATN inactivation and the distance of corresponding cannula placements from the location of a cannula yielding maximum behavioral deficit (in medial division of 
A
TRACE

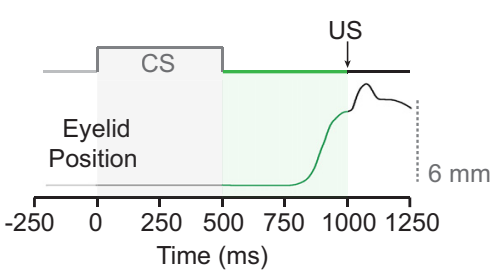

B

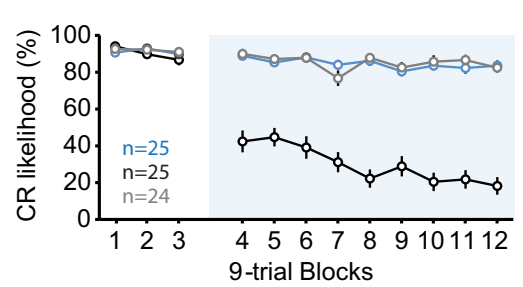

C

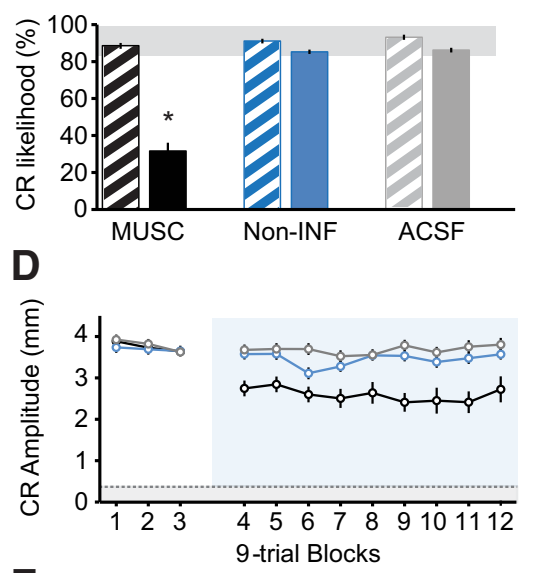

E

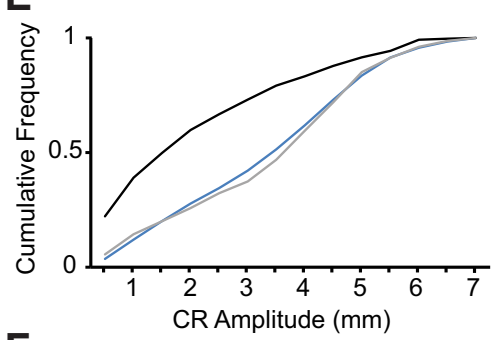

$\mathbf{F}$

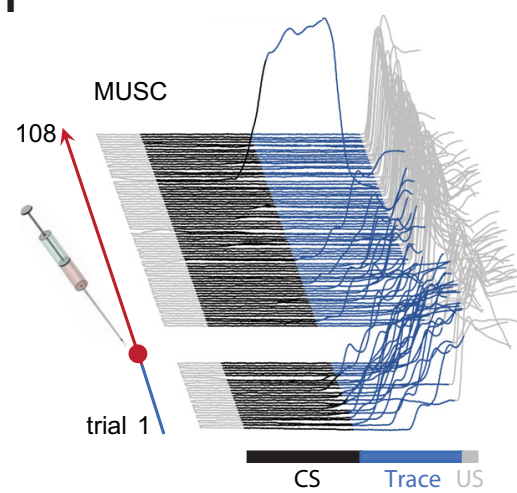

DELAY

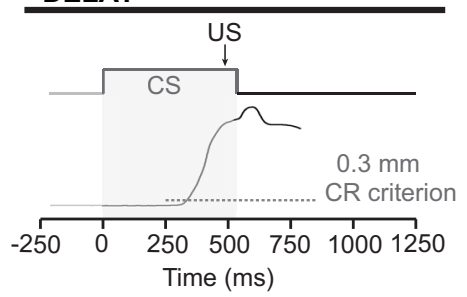

-0 -Non-INF -0 - MUSC -0 -ACSF

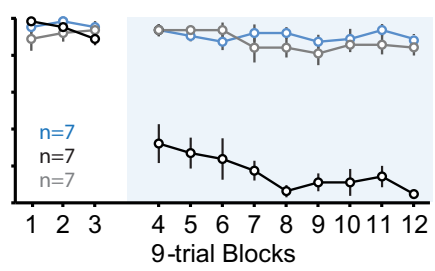

$\square$ Pre-infusion $\square$ Post-infusion Test

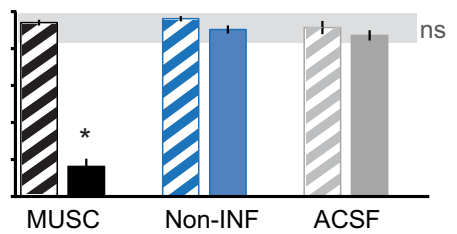

-o-Non-INF -0 - MUSC $-0-$ ACSF
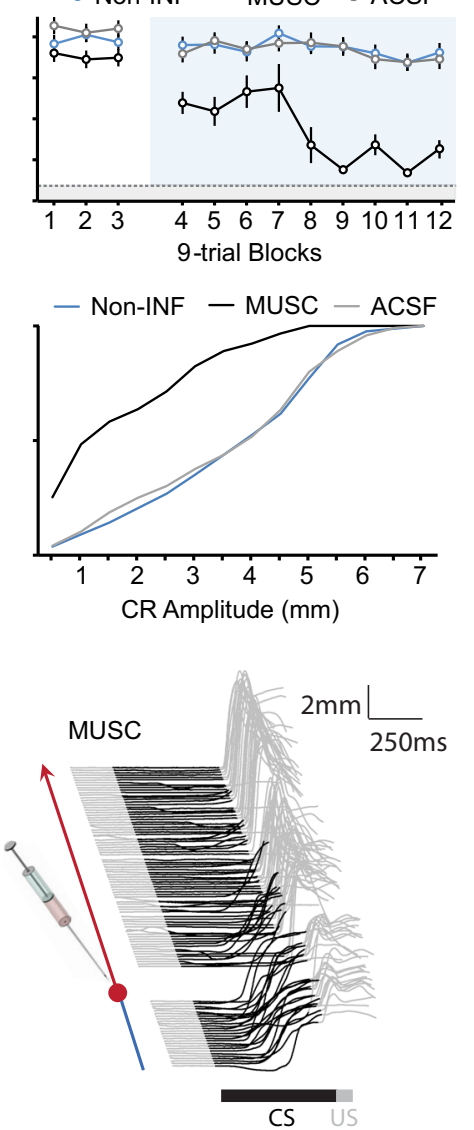

Figure 2. A, A schematic representation of delay and trace eyelid-conditioning stimuli and CRs of the eyelid. The example eyelid CRs show eyelid position as a function of time. With training, rabbits learn to make well timed eyelid responses (upward deflection indicates eyelid closure). The (R threshold criterion $(0.3 \mathrm{~mm})$ is indicated by the horizontal dotted line. $\boldsymbol{B}$, The average CR likelihood over 12 nine-trial training blocks of trace (left) and delay (right) conditioning on noninfusion (blue), muscimol infusion (black), and ACSF infusion (gray) sessions. Infusions occurred after the third block in each session (blue shading highlights the test phase). C, CR likelihood collapsed across blocks for preinfusion and postinfusion phases for trace (left) and delay (right) conditioning. The gray medial geniculate; Fig. $3 A, B)$. Linear regression was used to test the degree to which cannula location in each reference plane served to predict the postinfusion behavioral effect (Fig. $3 D$, individual planes). Informed by these regression analyses, the behavioral data were also separated into two groups based on cannula depth for further analysis using separate oneway ANOVAs comparing the three session types (muscimol, ACSF, and noninfusion) for each of the infusion phases followed by planned $t$ tests ( 12 conditions total; Fig. $4 A$ ). The significance level for all tests was $\alpha=0.01$ (two-tailed) except for the test of CR-onset latencies in vivo, which was $\alpha=0.05$ (two-tailed) since our hypothesis would be supported in the case of nonsignificance (Fig. 5). The Bonferroni method was used when appropriate to correct for type I errors associated with multiple comparisons. Descriptive statistics within the results represent the mean $\pm S D$. Error bars in all figures indicate \pm 1 SEM.

Computer simulations. We used a large-scale simulation of the cerebellum, previously demonstrated to capture many aspects of delay and trace eyelid conditioning (Hausknecht et al., 2017), to inform our interpretation of the behavioral effects of MATN inactivation. The simulation was composed of representations of the following numbers of each cerebellar cell type: 1024 mossy fibers, 1,048,576 granule cells, 1024 Golgi cells, 128 molecular layer interneurons (basket/stellate cells), 32 Purkinje cells, 8 deep cerebellar nuclei (DCN) cells, and 4 climbing fibers. Table 1 summarizes the number of neurons and the divergence and convergence ratios of each cell type represented in the simulation. Synaptic connectivity was determined by an algorithm that wired the network based on the known geometry, synaptic convergence ratios, and synaptic divergence ratios. To capture the geometric relationships and divergence and convergence ratios of the cerebellar cortex, granule cells, Golgi cells, and mossy fiber glomeruli were arranged in a twodimensional grid $(2048 \times 512$ for granule cells, $64 \times 16$ for Golgi cells, and $512 \times 128$ for glomeruli). We specified areas over which a simulated neuron could contact a member of the population of target cells. For granule cells as an example, the contact area was a long, nar-

\section{$\leftarrow$}

rectangle highlights nonsignificant pairwise comparisons $(\alpha=0.01)$, asterisks indicate significantly different groups. $D$, Average CR amplitudes (non-CRs excluded) by session type over 12 blocks during trace (left) and delay (right) conditioning. Blue shading indicates test phase, and gray shading indicates non-CR amplitude range. $\boldsymbol{E}$, Cumulative frequency plots of postinfusion CR amplitudes during trace (left) and delay (right) sessions. $\boldsymbol{F}$, Representative raw data examples of muscimol infusion effects for trace (left) and delay (right) during muscimol infusion sessions. Sweeps represent eyelid position as a function of time over the 108 trials of a daily session. Color coding of trials was as follows: gray, pre-CS baseline; black, CS interval; blue, trace interval; gray, US/post-US interval. Red dots indicate time of infusion, red lines indicate postinfusion test phase. 
A

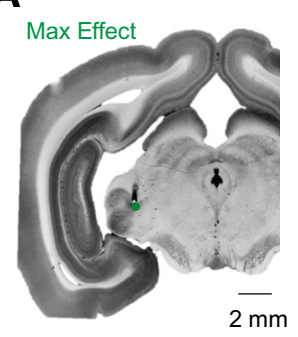

B

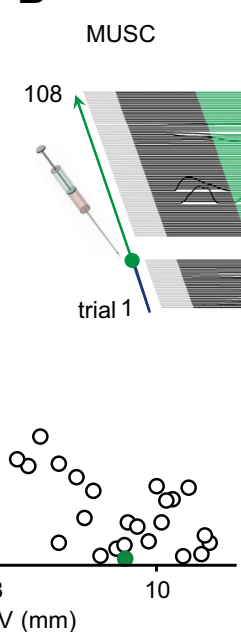

D

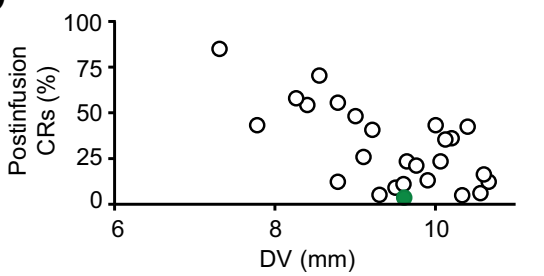

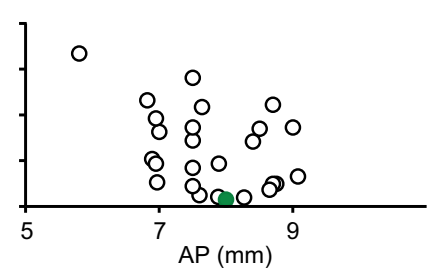

C

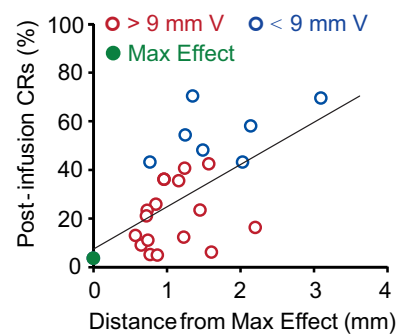

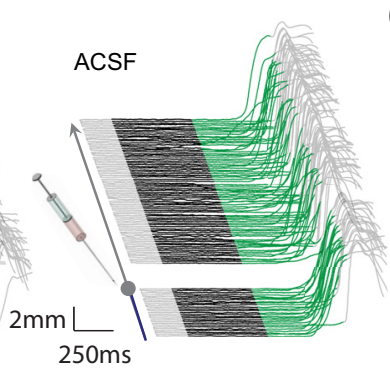

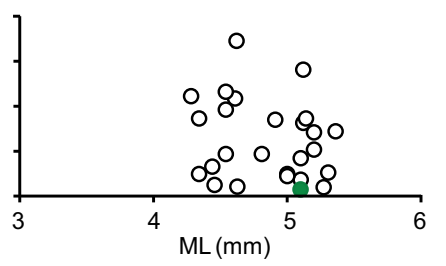

Figure 3. A, Coronal section of the MATN showing cannula placement in the medial division of the medial geniculate nucleus for the Max Effect. Cannula tip location is indicated as a green dot. $\boldsymbol{B}$, Raw data for the Max Effect placement on MUSC and ACSF infusion days for trace conditioning. Sweeps represent eyelid position as a function of trial time: gray, Pre-CS; black, CS; green, trace interval; gray, post-US. C, Scatterplot of postinfusion CR likelihood (\%) as a function of total distance (mm) of cannula tips relative to Max Effect placement (green dot). Points are color coded based on depth ventral from brain surface: red, $>9 \mathrm{~mm}$; blue, $<9 \mathrm{~mm}$. D, Postinfusion CR likelihood plotted as a function of cannula tip location in the DV (left), AP (center), and ML (right) planes.

row rectangle defined on the long side by the length of the granule cell axons (the parallel fibers) and defined on the short side by two diameters of Golgi cell apical dendrites. For each granule cell, all of its synapses onto Golgi cells were determined by its position on the grid and by its contact area. The number of connections made within this area was then determined by the divergence ratio of the granule-to-Golgi connection, by how many Golgi cells each granule cell contacts. Candidate connections were determined randomly within the contact area. Candidate connections were then tested to ensure that making that connection did not violate the convergence ratio of granule-to-Golgi connections, the number of inputs from granule cells received by each Golgi cell. If a Golgi cell already had its allotment of granule cell inputs, then the algorithm chose a new candidate as a replacement. This process was repeated until all appropriate connections were formed and stored. One consequence of this process is that each network is wired differently (unless the same random number seed was used) even though the same rules were used. Each network could be stored on disk and reloaded later in precisely the same state (e.g., connectivity, activity). This enabled separate tests to be implemented on exact copies of the same network, when appropriate.

Neurons were implemented as conductance-based point neurons. Active conductances were omitted and mimicked by rules for varying threshold based on recent activity. Thus, the membrane potential of each cell was calculated based on synaptic and leak conductances. Synaptic conductances were simulated by using step increases on a spike in the presynaptic cell followed by an exponential decay with time constants derived from in vitro recording studies. Spikes were initiated when the membrane potential exceeded threshold. The threshold for spike initiation changed with spiking history to mimic absolute and relative refractory periods, and other properties such as spike adaptation when appropriate. The time step for calculating the membrane potential was $1 \mathrm{~ms}$.

Learning-related plasticity was implemented in the following two classes of synapses: the granule cell synapses onto Purkinje cells and mossy fiber synapses onto the DCN neurons. At the granule-to-Purkinje synapse, plasticity was controlled by climbing fiber input (Ito and Kano, 1982; Lev-Ram et al., 2002, 2003; Coesmans et al., 2004). Synapses were eligible to undergo either long-term depression (LTD) or long-term potentiation (LTP) when strongly active. Synapses active within a 100-ms time window preceding a climbing fiber input (Raymond and Lisberger, 1998; Safo and Regehr, 2008) underwent LTD, whereas synapses active at other times underwent LTP. The magnitude of the weight changes pro- duced by these events was small, and the ratio of increases to decreases was adjusted to produce a self-regulating $1-\mathrm{Hz}$ level of spontaneous climbing fiber activity before training. Mossy fiber-to-DCN synapse strength was under the control of Purkinje cell activity (Mauk and Donegan, 1997; Medina and Mauk, 1999; Pugh and Raman, 2006, 2008). Mossy fiber-to-DCN synapses active within a time window of an abrupt pause in Purkinje cell activity underwent LTP. These synapses underwent LTD when active during strong Purkinje cell activity.

Eyelid conditioning training was simulated by increasing the activity of $3 \%$ of the mossy fibers to represent a $500-\mathrm{ms}$ tone CS (Boyd and Aitkin, 1976; Aitkin and Boyd, 1978; Sears and Steinmetz, 1991; Freeman and Muckler, 2003). To engage trace conditioning another $1 \%$ of the mossy fibers were activated to simulate the activity of mossy fibers driven by persistent input (Takehara-Nishiuchi and McNaughton, 2008; Kalmbach et al., 2010; Siegel et al., 2012). The activity of these cells increased at CS onset and lasted for $1 \mathrm{~s}$. This CS-related and persistentlike activity occurred against a background of activity in the remaining mossy fibers. This was accomplished by assigning the remaining mossy fibers a range of average firing rates that were unchanged by the presentation of the CS. Mossy fiber spikes were generated from a Poisson spike generator. US-driven climbing fiber input was simulated by presenting a brief excitatory conductance to the climbing fiber. The output of the simulation was represented by inferring a virtual eyelid response from the activity of the eight deep cerebellar nuclei cells.

Following acquisition training, we presented the simulation with three 100 -trial probe sessions using $100 \%$ of mossy fiber inputs from each population represented in a given probe (CS and/or persistent; Fig. 6). During these probe sessions, climbing fibers were no longer activated by the US and synaptic plasticity was disabled to avoid changes in synaptic weight that might be caused by the inputs presented. During the first probe session, the simulation was presented with CS-duration mossy fiber inputs only. The second probe session consisted of persistentduration mossy fiber inputs only, and the third session consisted of CSduration and persistent-duration inputs presented together, such that both inputs were presented at the beginning of each trial and the CS input ended $500 \mathrm{~ms}$ before the persistent-duration input. To simulate possible input patterns resulting from partial inactivation of the target nuclei, we also presented 12 additional 100-trial probe sessions using various combinations of graded mossy fiber activation levels $(75 \%, 50 \%$, or $25 \%$ of mossy fibers active) in each of the two mossy fiber populations (CS and persistent). Proportions of each mossy fiber response population (se- 

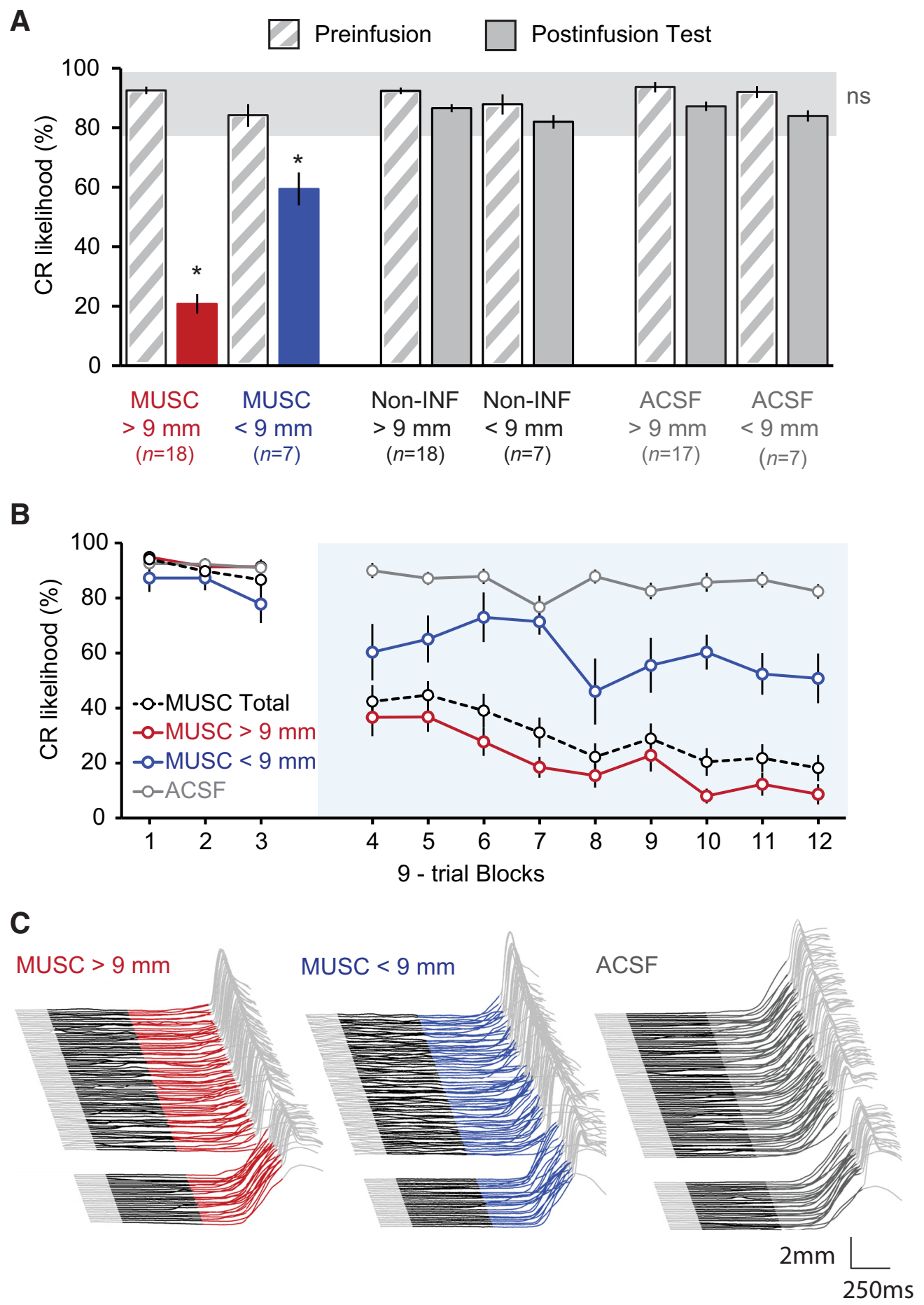

Figure 4. Effect of MATN inactivation on trace (Rs based on cannula depth. Muscimol (MUSC) effects are separated into the following two groups (color coded): $>9 \mathrm{~mm}$ (red) and $<9$ $\mathrm{mm}$ (blue) ventral to brain surface. $A$, Average CR likelihoods for preinfusion and postinfusion periods used in pairwise comparisons (Table 3 ). Gray shaded region at the top of the plot highlights values that were not significantly different. Asterisks indicate $p<0.01$. B, Average CR likelihood across preinfusion test (1-3) and postinfusion test (4-12) training blocks. Data from collapsed MUSC group (black dotted) and ACSF infusion (gray) sessions are shown for reference. Blue shading highlights the postinfusion test phase. $C$, Average behavior from the $>9 \mathrm{~mm}$ MUSC, $<9 \mathrm{~mm}$ MUSC, and ACSF groups color coded as in $\boldsymbol{A}$ and $\boldsymbol{B}$.

quentially assigned during acquisition via a random number generator) that were not active for graded probe sessions were reassigned to the background mossy fiber population, which do not respond to conditioning input. The graded probes tested one of the following four categories: (1) partial inactivation of persistent-duration mossy fiber inputs only; (2) partial inactivation of persistent-duration mossy fiber inputs presented with $100 \%$ of tone-duration mossy fiber inputs activated; (3) partial inactivation of CS-duration mossy fiber inputs presented with
$100 \%$ of persistent-like mossy fiber inputs activated; and (4) equivalent partial inactivation proportions within both CS- and persistent-duration mossy fiber inputs. Prior stimulation and simulation data have shown that CS-duration mossy fiber inputs alone are not sufficient for trace CRs (Kalmbach et al., 2010, 2011), and we did not include graded probes for tone-duration inputs alone for these reasons. Average CR likelihoods, amplitudes, and onset latencies were computed for each of the 15 total probe sessions (Fig. 7). 


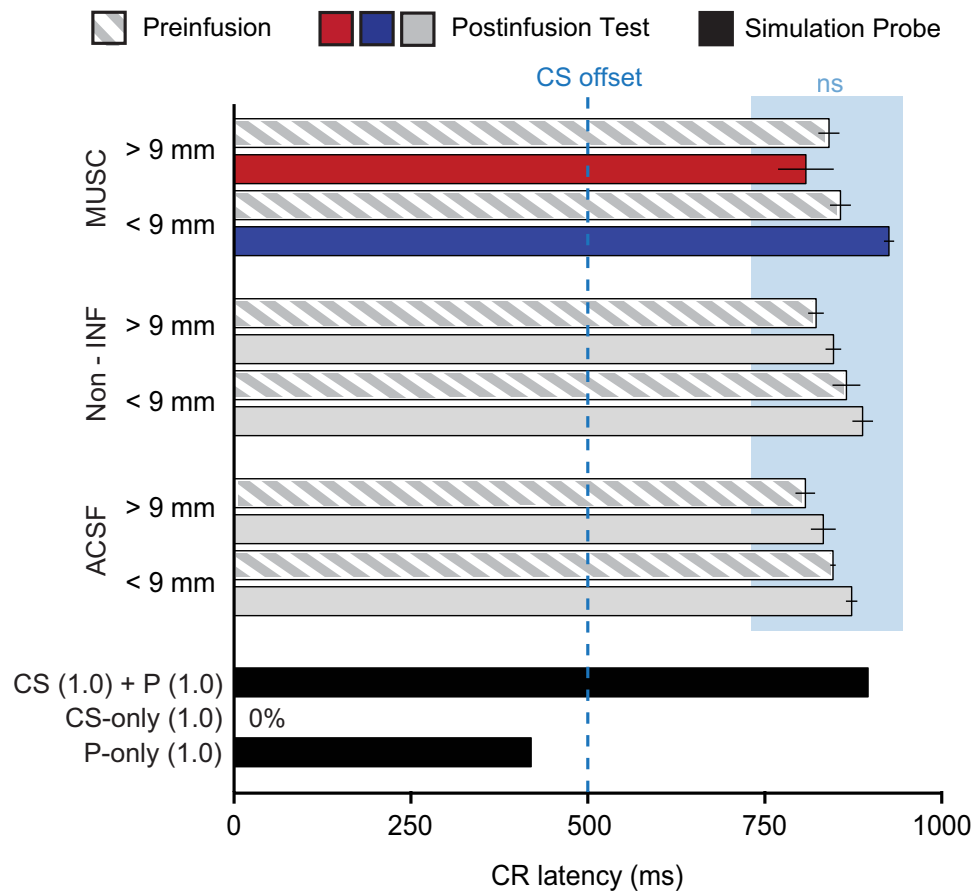

Figure 5. Average $\mathrm{CR}$ latency to onset during trace conditioning. In vivo behavioral data are grouped by preinfusion and postinfusion periods for each cannula depth ( $>9$ or $<9 \mathrm{~mm}$ ventral). All conditions show well timed (Rs. The blue-shaded region highlights latencies that did not differ significantly $(p>0.05)$. Simulation CR latency averages for the following three probe sessions: persistent (P)-only, CS-only, and compound CS/persistent probe sessions with $100 \%$ of respective mossy fibers active are represented below for reference (black). CS offset is indicated for trial timing reference (cyan dotted line).

Table 1. Connectivity in the computer simulation

\begin{tabular}{|c|c|c|}
\hline Cell type $(n)$ & Input source $(+/-): n$ & Output target $(+/-): n$ \\
\hline Mossy fibers (1024) & NA & $\begin{array}{l}\text { To granule }(+): 4096 \\
\text { To DCN }(+): 1 \\
\text { To Golgi cell }(+): 64\end{array}$ \\
\hline Climbing fibers (4) & $\begin{array}{l}\text { From } D C N(-): 8 \\
\text { From climbing fibers }(C): 7\end{array}$ & $\begin{array}{l}\text { To Purkinje cell }(-): 8 \\
\text { From climbing fibers }(\mathrm{C}): 7\end{array}$ \\
\hline Granule cells $(1,048,576)$ & $\begin{array}{l}\text { From mossy fibers }(+): 4 \\
\text { From Golgi }(-): 3-4\end{array}$ & $\begin{array}{l}\text { To Purkinje cell }(+): 1 \\
\text { To Golgi cell }(+): 4 \\
\text { To basket }(+): 1 \\
\text { To stellate }(+): 1\end{array}$ \\
\hline Golgi cells (1024) & $\begin{array}{l}\text { From mossy fibers }(+): 16 \\
\text { From granule }(+): 4096 \\
\text { From Golgi }(-): \sim 4(0-8) \\
\text { From Golgi }(C): \sim 1(0-8)\end{array}$ & $\begin{array}{l}\text { To granule }(-): 3072 \\
\text { To Golgi cell }(-): \sim 4(0-8) \\
\text { To Golgi cell }(C): \sim 1(0-8)\end{array}$ \\
\hline Purkinje cells (32) & $\begin{array}{l}\text { From granule }(+): 32768 \\
\text { From stellate }(-): 16 \\
\text { From basket }(-): 16\end{array}$ & $\begin{array}{l}\text { To DCN }(-): 3 \\
\text { To basket }(-): 16\end{array}$ \\
\hline DCN (8) & $\begin{array}{l}\text { From mossy fibers }(+): 128 \\
\text { From Purkinje cell }(-): 12\end{array}$ & $\begin{array}{l}\text { To climbing fibers }(-): 4 \\
\text { To granule }(+): \sim 16,384 \text { (collat) } \\
\text { To Golgi cell }(+): \sim 256 \text { (collat) }\end{array}$ \\
\hline Stellate cells (512) & From granule $(+): 2048$ & To Purkinje cell $(-): 1$ \\
\hline Basket cells (128) & From granule $(+): 8192$ & To Purkinje cell (-): 4 \\
\hline
\end{tabular}

NA, Not applicable; +, excitatory; - , inhibitory; C, coupling; collat, collaterals.

\section{Results}

\section{Effect of MATN inactivation on expression of} eyelid responses

Trace CR likelihood

Inactivation of the MATN via infusion of muscimol in well trained rabbits significantly attenuated the expression of trace eyelid responses (all cannula placements, $n=25$; Fig. $2 B, C$, F, left column). After muscimol infusion, CR likelihood decreased gradually across blocks (Fig. 2B, left column), presumably reflecting the diffusion of the muscimol. These effects were fully reversible as CRs returned to normal control levels in the days following muscimol infusion session (data not shown). All cannula placements were included (regardless of location) and are summarized in Figure 1.

To quantify these effects, conditioned responding (expressed as CR likelihood) was analyzed using a session type (muscimol vs ACSF control vs noninfusion) by session phase (preinfusion vs postinfusion test) $3 \times 2$ repeated-measures ANOVA (Fig. 2C). This analysis revealed significant main effects of session type and session phase, and a significant session type by phase interaction (Table 2). Pairwise comparisons indicated that $\mathrm{CR}$ likelihood following muscimol infusion $(n=25)$ was significantly lower than noninfusion $(n=25)$ and $\operatorname{ACSF}(n=$ 24) sessions (both comparisons $p<$ $0.00001)$. Control tests indicate that the behavioral effect was specific to muscimol infusion and was not attributable to the infusion procedures, per se. Postinfusion ACSF and noninfusion sessions did not differ $(p=0.49)$. There were also no significant differences in preinfusion CR likelihood (muscimol vs noninfusion, $p=0.60$; muscimol vs ACSF, $p=$ 0.11 ; noninfusion vs ACSF, $p=0.27$ ). Together, these data demonstrate that MATN are necessary for the normal expression of CRs in trace eyelid conditioning.

\section{Delay CR likelihood}

Previous studies in rodents have demonstrated that the MATN are necessary for the expression of conditioned responses during delay eyelid conditioning with a tone (e.g., Halverson and Freeman, 2006; Halverson et al., 2008). To verify that the necessity of MATN for auditory eyelid conditioning is conserved across species, we used a subset of subjects $(n=7)$ with effective cannula placements to test the hypothesis that the MATN are necessary for the expression of delay responses in rabbits as well. These animals were retrained with a different CS ( $9.5 \mathrm{kHz}$ tone) for $2-7$ $\mathrm{d}$ with delay-conditioning procedures [interstimulus interval $($ ISI $)=500]$, over which time they acquired robust CRs (stable responding across session, $>80 \%$ CRs). The altered timing of these CRs provides strong evidence that they are the result of delay conditioning and not some form of residual trace responses. The average CR latency of the trace responses (using a $1000 \mathrm{~ms}$ ISI) was $850 \pm 106 \mathrm{~ms}$, whereas with a $500 \mathrm{~ms}$ ISI (delay CR onset times must be earlier than $500 \mathrm{~ms}$ ) the average CR latency was $318 \pm 80 \mathrm{~ms}$.

Rabbits were tested using the same sequence of sessions as that used for the trace-conditioning test (noninfusion session, followed by a muscimol infusion session and an ACSF infusion session that were counterbalanced; $n=7$ for each condition). Muscimol infusions produced a progressive decline in CR expression throughout the delay-conditioning infusion sessions (Fig. $2 B$, right). As with CR likelihood data for trace conditioning, a $3 \times 2$ repeated-measures ANOVA revealed significant main 
effects of session type and phase, and a significant session type by phase interaction (Fig. 2C, right, Table 2). Pairwise comparisons again revealed that postinfusion muscimol CR likelihood was significantly lower than for noninfusion and ACSF infusion sessions (both $p<$ 0.00001), while noninfusion and ACSF session performance levels did not differ significantly $(p=0.44)$. Preinfusion CR likelihoods did not differ for the three session types (muscimol vs noninfusion, $p=$ 0.32 ; muscimol vs ACSF, $p=0.58$; noninfusion vs ACSF, $p=0.27$ ). These data demonstrate that MATN are necessary for the expression of CRs in delay eyelid conditioning in rabbits.

\section{Trace and delay CR amplitudes}

With the decreased CR likelihood produced by inactivation of MATN there is inherently a decrease in average CR amplitude, which could reflect an overall decrease in the amplitude of the remaining CRs or simply reflect a lower likelihood of normal-sized CRs. To disambiguate this, we eliminated the non-CRs to calculate the preinfusion and postinfusion amplitudes of the CRs. CR amplitudes grouped by session type (Fig. 2D,E) showed significant attenuation following muscimol infusions during trace (Fig. 2D,E, left) and delay (Fig. 2D,E, right) eyelid conditioning. Figure $2 D$ shows average CR amplitudes for each session type broken down by training block. During trace conditioning (Fig. 2D, left), CR amplitudes following muscimol infusions were lower throughout the postinfusion test phase relative to preinfusion and to postinfusion control amplitudes. Analysis of CR amplitude during delay conditioning (Fig. $2 D$, right) produced a similar pattern of results. One animal was not included in the delay muscimol sample due to complete CR blockade (only non-CRs during the test phase). While CR amplitude decreases (Fig. 2D) appeared to be magnified during delay relative to trace infusions, this difference was attributable to the fact that the delay data represented a biased subset of the trace animals that had a strong behavior effect. Limiting the quantification of trace CR amplitudes to the same subset of animals used for the delay experiment increased the magnitude of the muscimol effect on trace CR amplitudes to levels equivalent to those observed in delay $(n=6, p=0.77)$. Figure $2 E$ shows cumulative frequency distributions of CR amplitudes during the postinfusion test phase. For both trace and delay, there was a larger proportion of
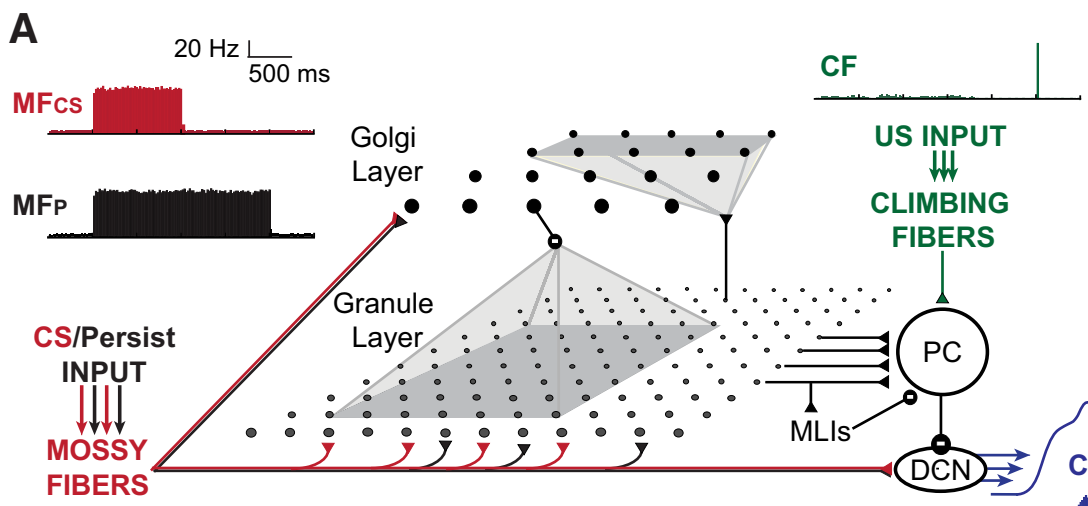

US INPUT Wt CLIMBING FIBERS
B

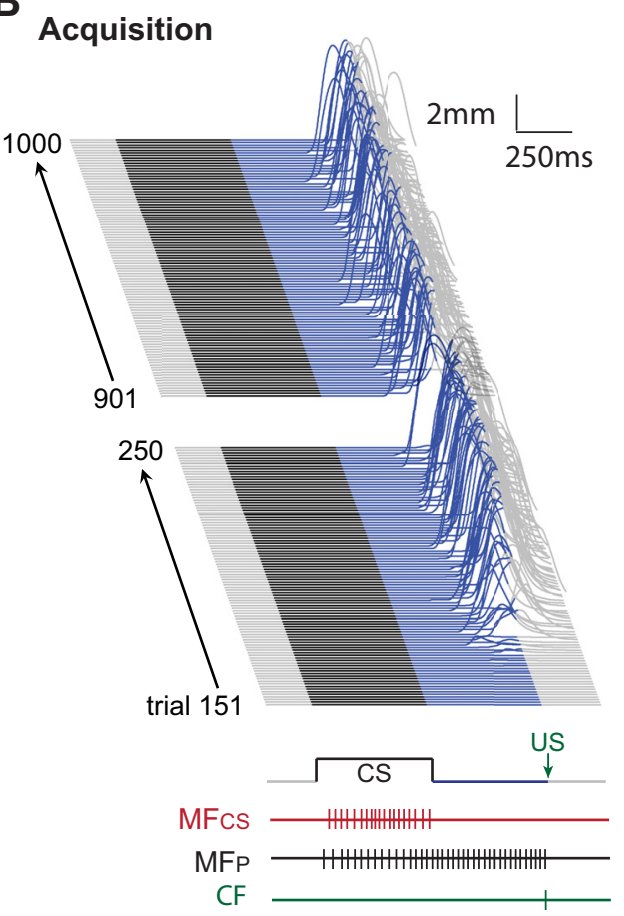

D

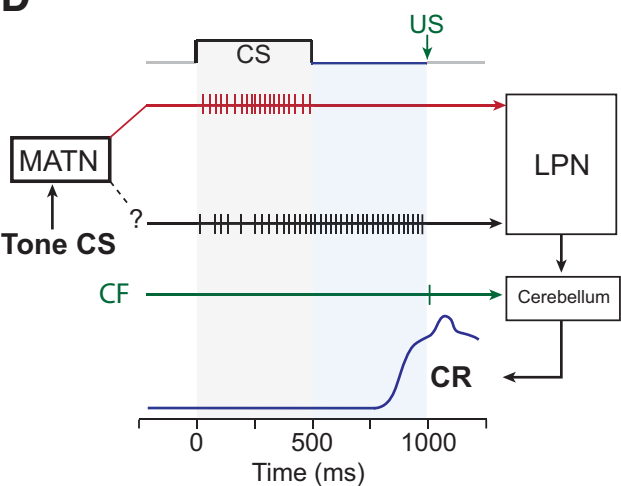

C

Probes

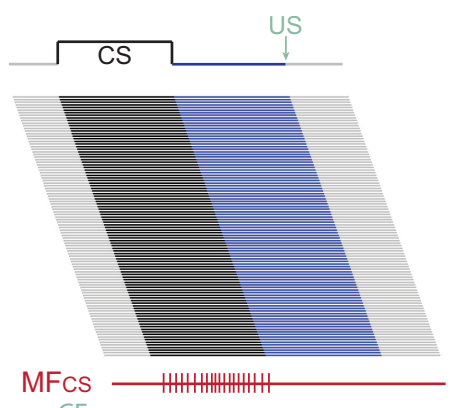

CF

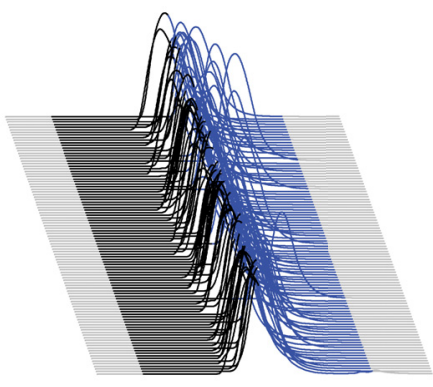

MFP

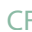

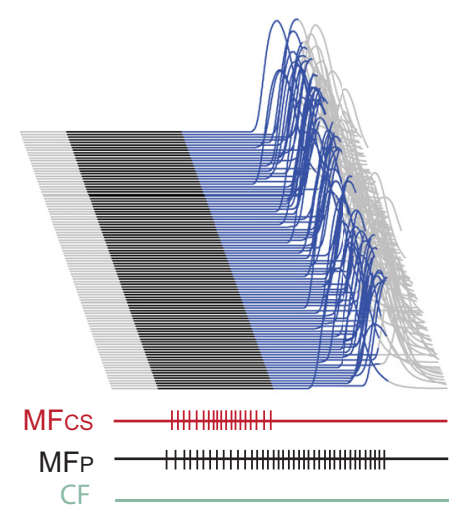

Figure 6. Large-scale cerebellar simulations predict that both tone-driven and persistent-like mossy fiber inputs to cerebellum are necessary for trace conditioning. $A$, Simplified diagram of cerebellar inputs, outputs, and internal connectivity modeled in the simulation (MFCs, CS mossy fibers; MLLs, molecular layer interneurons; MFp, persistent mossy fibers; PC, Purkinje cells). $\boldsymbol{B}$, Simulated inputs and corresponding behavioral output (predicted eyelid position as a function of time) during acquisition. (S-evoked compound mossy fiber inputs (CS- and persistent-duration) are presented with US-evoked climbing fiber (CF) inputs. Trials show a period of initial CR acquisition (trials 151-250), and the final behavioral asymptote reached (93\% CRs, trials 901-1000). C, Simulated inputs and predicted eyelid responses for three different probe tests: CS-duration mossy fiber inputs only, persistent-duration mossy fiber input only, or both. D, Schematic of relevant circuitry and inputs for cerebellar learning of trace conditioning. LPN, Lateral pontine nucleus. 
A

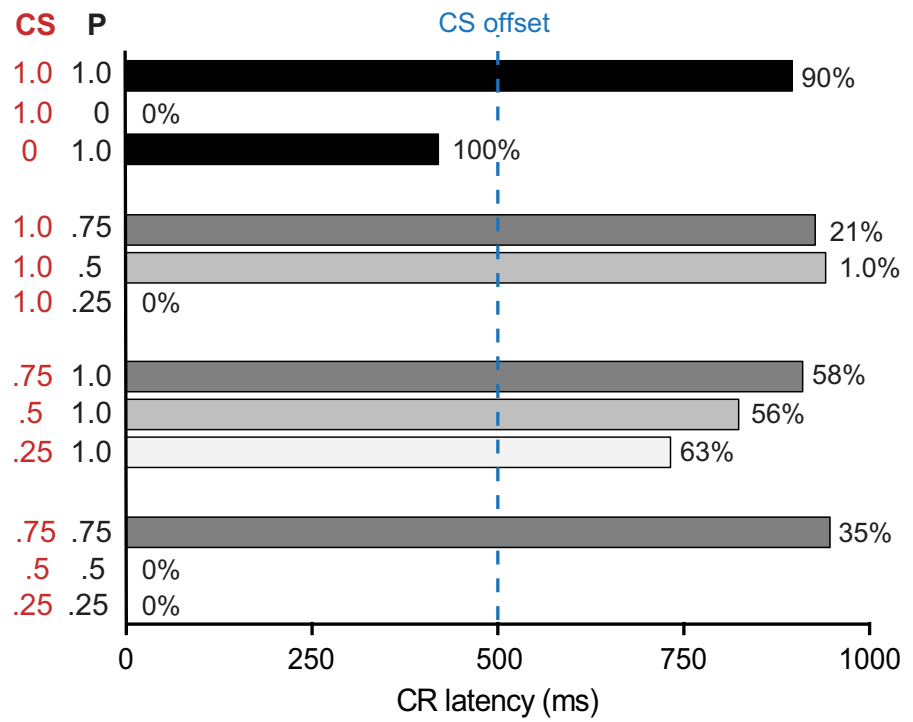

B

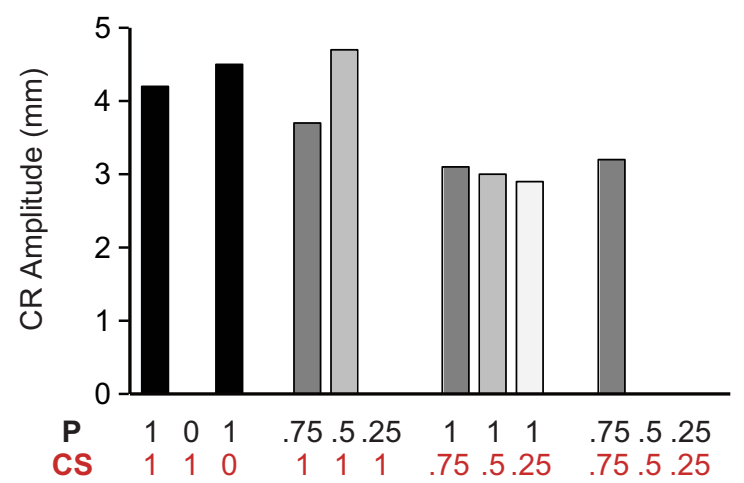

Figure 7. $\quad(R$ output measures for simulated probe conditions. A, Average $C R$ onset latency (bars) and corresponding $C R$ likelihood (\%) for each probe session. CR latencies for persistent (P)-only, CS-only, and compound CS/persistent probe sessions with $100 \%$ of respective mossy fibers active are represented in black. Latencies for the remaining probe conditions are coded in grayscale according to the degree of $\mathrm{P}$ and/or CS mossy fiber activation in the graded population (darker grays indicate larger proportions of activation for the manipulated mossy fiber populations, lighter grays indicate smaller proportions of activation). Activated proportion values for $\mathrm{CS}$ (red) and $\mathrm{P}$ (black) mossy fiber populations are indicated on the $y$-axis. CS offset is indicated for trial timing reference (cyan dotted line). $\boldsymbol{B}$, Average $(R$ amplitudes for each probe condition represented in $\boldsymbol{A}$. Amplitude and latency measures exclude non-CR trial data.

Table 2. ANOVA results for trace and delay infusion experiments

\begin{tabular}{|c|c|c|c|}
\hline & \multirow[b]{2}{*}{ Delay } & \multicolumn{2}{|l|}{ Trace } \\
\hline & & $\begin{array}{l}\text { All } \\
\text { placements }\end{array}$ & $\begin{array}{l}\text { Grouped by } \\
\text { placement depth }\end{array}$ \\
\hline Session type main effect & $\begin{array}{c}F_{(2,12)}=111.79 \\
p<0.00001\end{array}$ & $\begin{array}{c}F_{(2,48)}=116.18 \\
p<0.00001\end{array}$ & \\
\hline Phase main effect & $\begin{array}{r}F_{(1,6)}=163.88 \\
p<0.00001\end{array}$ & $\begin{array}{c}F_{(1,24)}=186.05 \\
p<0.00001\end{array}$ & \\
\hline Session type $\times$ phase & $\begin{array}{c}F_{(2,12)}=112.46 \\
p<0.00001\end{array}$ & $\begin{array}{c}F_{(2,48)}=101.90 \\
p<0.00001\end{array}$ & \\
\hline Preinfusion & & & $\begin{array}{c}F_{(5,68)}=2.15 \\
p=0.07\end{array}$ \\
\hline Postinfusion & & & $\begin{array}{r}F_{(5,68)}=96.78 \\
p<0.00001\end{array}$ \\
\hline
\end{tabular}

small CR amplitudes following muscimol infusions compared with control sessions. Kolmogorov-Smirnov tests showed that the CR amplitude distribution for muscimol was significantly different from the noninfusion (trace, $p<0.00001$; delay, $p<0.00001$ ) and ACSF (trace, $p<0.00001$; delay, $p<0.00001$ ) amplitude distribu- tions, while control session distributions did not differ significantly (trace, $p=0.04$; delay: $p=0.167)$. Figure $2 F$ shows representative data from muscimol infusion sessions for trace and delay. These data demonstrate for both delay and trace eyelid conditioning that MATN inactivation decreases the mean amplitude of residual CRs.

\section{Site of muscimol action}

Using the complete trace-conditioning dataset, we found a systematic relationship across subjects between the placement of the cannula and the magnitude of the behavioral effect of muscimol infusions. This provides an opportunity to refine the estimates of the precise site of action of muscimol. To determine the region where muscimol infusion produces these effects on CR expression, we identified the cannula placement that yielded the maximum behavioral effect (Max Effect; Fig. 3A). This subject (Fig. 3B) showed strong preinfusion CRs (100\%), followed by a near complete abolition of postinfusion CRs (3.7\%, or three CRs in 81 trials), and robust post-ACSF infusion CRs (78.0\%). The Max Effect cannula site was located in the medial division of the medial geniculate nucleus (Figs. $1 D, E$, $3 A$, green dot). The behavioral effects of the remaining placements were then analyzed with respect to the distance from this Max Effect cannula location. For each remaining subject, we calculated the $3-\mathrm{D}$ distance between the cannula placement and the Max Effect placement and plotted this against the postinfusion CRs during muscimol sessions (Fig. 3C). This revealed a significant positive correlation between postinfusion CR likelihood and the distance of cannula placements from Max Effect $(r=0.58, p=0.0022)$.

To understand the essential anatomical features of effective cannula placements, we assessed the degree to which the reduction in CR likelihood could be predicted by cannula location within each of the three stereotaxic reference planes. A multiple linear regression was calculated to predict postmuscimol CR likelihoods based on cannula location within each of the three coordinate planes: DV (top), AP (middle), and ML (bottom) projections relative to brain surface, bregma, and midline, respectively (Fig. 3D). Results indicated that $51.3 \%$ of the variance was explained by the regression equation $\mathrm{CR}$ likelihood = $6186.48-15.85(\mathrm{DV})-3.68(\mathrm{AP})-1.38(\mathrm{ML}),\left(\right.$ adjusted $R^{2}=$ $\left.0.44, F_{(3,21)}=7.38, p=0.0015\right)$. Cannula depth (DV) was a significant predictor of post-muscimol infusion CR likelihood $(\beta=-0.64, p=0.003)$, while AP and ML projections were not (AP: $\beta=-0.02, p=0.43$; ML: $\beta=-0.14, p=0.91$ ). We also tested for the possibility of nonlinear relationships, finding no additional significant predictive terms.

Cannula placements that produced robust behavioral effects (postinfusion CRs of $<44 \%$ ) were located in or just ventral to the right MATN (Fig. 1). To illustrate the site of action, summary 
Table 3. Pairwise comparisons of average CR likelihood data for preinfusion and postinfusion periods separated by infusion depth

\begin{tabular}{|c|c|c|c|c|c|c|}
\hline & \multicolumn{2}{|l|}{ MUSC } & \multicolumn{2}{|l|}{ Non-INF } & \multicolumn{2}{|l|}{ ACSF } \\
\hline & $>9 \mathrm{~mm}$ TEST & $<9 \mathrm{~mm}$ TEST & $>9 \mathrm{~mm}$ TEST & $<9 \mathrm{~mm}$ TEST & $>9 \mathrm{~mm}$ TEST & $<9 \mathrm{~mm}$ TEST \\
\hline MUSC $>9 \mathrm{~mm}$ PRE & $6.5 \mathrm{E}-113^{*}$ & $2.31 \mathrm{E}-21^{*}$ & 0.044 & 0.008 & 0.079 & 0.031 \\
\hline MUSC < $<$ mm PRE & $2.31 \mathrm{E}-51^{*}$ & $2.87 \mathrm{E}-10^{*}$ & 0.553 & 0.671 & 0.447 & 0.973 \\
\hline Non-INF $>9 \mathrm{~mm}$ PRE & $1.9 \mathrm{E}-112^{*}$ & $3.27 \mathrm{E}-21^{*}$ & 0.054 & 0.009 & 0.088 & 0.034 \\
\hline Non-INF $<9$ mm PRE & $3.76 \mathrm{E}-57^{*}$ & $2.00 \mathrm{E}-12^{*}$ & 0.762 & 0.225 & 0.891 & 0.425 \\
\hline ACSF $>9 \mathrm{~mm}$ PRE & $9.04 \mathrm{E}-113^{*}$ & $5.09 \mathrm{E}-22^{*}$ & 0.021 & 0.004 & 0.040 & 0.017 \\
\hline ACSF $<9 \mathrm{~mm}$ PRE & $4.73 \mathrm{E}-65^{*}$ & $1.61 \mathrm{E}-15^{*}$ & 0.130 & 0.027 & 0.184 & 0.070 \\
\hline MUSC $>9 \mathrm{~mm}$ TEST & & $2.81 \mathrm{E}-15^{*}$ & $1.48 \mathrm{E}-95^{*}$ & $3.39 \mathrm{E}-48^{*}$ & $8.58 \mathrm{E}-95^{*}$ & $4.28 \mathrm{E}-51^{*}$ \\
\hline MUSC $<9 \mathrm{~mm}$ TEST & & & $5.98 \mathrm{E}-16^{*}$ & $3.92 \mathrm{E}-09^{*}$ & $2.73-16^{*}$ & $3.59 \mathrm{E}-10^{*}$ \\
\hline Non-INF $>9 \mathrm{~mm}$ TEST & & & & 0.257 & 0.833 & 0.524 \\
\hline Non-INF $<9$ mm TEST & & & & & 0.194 & 0.698 \\
\hline ACSF $>9 \mathrm{~mm}$ TEST & & & & & & 0.421 \\
\hline
\end{tabular}

Values are given as raw $p$ values. ACSF, ACSF session; MUSC, muscimol session; Non-INF, non-infusion session; PRE, preinfusion phase; TEST, postinfusion test phase.

*Bonferroni-corrected significance at $\alpha=0.01$; Bonferroni-corrected critical value: $p=1.97 \mathrm{e}-04$.

histology data coded by postinfusion behavioral effect (regardless of location) are presented in a parasagittal composite (Fig. 1D) and serial coronal sections (Fig. $1 E$ ). In Figure $1, D$ and $E$, the green dots indicate the cannula placement that produced the Max Effect, the yellow dots indicate placements with $<44 \%$ postinfusion CRs (20.8 $\pm 4.7 \%$ CRs), and the gray dots indicate placements with $>44 \%$ postinfusion CRs $(60.1 \pm 9.5 \%$ CRs $)$. Example placements from each of these two behavioral effect categories are shown in Figure 1C. A reconstructed composite in the sagittal plane (Fig. 1D; section taken at $4.5 \mathrm{~mm}$ lateral to midline) illustrates the importance of placement being deeper than $9 \mathrm{~mm}$ ventral to brain surface (Fig. $1 D$, gray dotted line). For behavioral effects in which postinfusion CRs were $<44 \%$ CRs per block, all placements were ventral to $9 \mathrm{~mm}$ from brain surface except one. However, this more dorsal placement $(8.78 \mathrm{~mm}$ ventral to brain surface) required a larger infusion volume to produce a robust behavioral deficit. For this reason, this data point was not included in the summary analyses.

\section{Behavioral effects of infusion depth during trace conditioning}

An additional analysis examining the effects of cannula depth across all placements was performed - in part as a further refinement of the key site of muscimol action and in part to allow the analysis of CR timing for responses attenuated but not abolished by MATN inactivation. To do so, rabbits were divided into two groups corresponding to cannula placements greater than (Fig. 4, red; $n=18$ for muscimol and noninfusion, $n=17$ for ACSF) or less than (Fig. 4, blue; $n=7$ for all conditions) $9 \mathrm{~mm}$ ventral to brain surface. In general, the deeper cannula placements produced more robust effects on the expression of trace CRs. A oneway ANOVA comparing CR likelihood data during postinfusion test phase for muscimol, ACSF, and noninfusion sessions at the two cannula depth ranges ( $>9$ and $<9 \mathrm{~mm}$ ventral to brain surface) revealed significant differences $\left(F_{(5,68)}=96.78, p<\right.$ 0.00001; Fig. $4 A$ ). In contrast, a one-way ANOVA assessing CR likelihood data during preinfusion phase (blocks 1-3) among these conditions revealed no significant differences $\left(F_{(5,68)}=\right.$ 2.15, $p=0.07$; Fig. $4 A$, striped bars). Pairwise comparisons showed that CR likelihood during the test phase was significantly lower for the $>9 \mathrm{~mm}$ muscimol group compared with the $<9$ mm muscimol group. CR likelihood for both groups was significantly lower than all other groups-noninfusion (preinfusion and postinfusion, both depths) and ACSF infusions (preinfusion and postinfusion, both depths; Table 3, complete summary with specific $p$ values). Thus, the most robust effects on CR likelihood were produced by placements at or just below the medial division of the medial geniculate nucleus. CRs were often completely abolished for these deeper infusions sites. Progressive decline in average CR likelihood occurred over subsequent postinfusion training blocks reaching $<10 \%$ CRs by the end of the training session for the $>9 \mathrm{~mm}$ group (Fig. $4 B$ ). Figure $4 C$ shows the average behavior sessions (eyelid position averaged point by point as a function of time) for the $>9 \mathrm{~mm}$ muscimol, $<9 \mathrm{~mm}$ muscimol, and ACSF groups (combined over cannula depth).

Previous experimental and simulation studies, as well as the simulation results presented in the next section, highlight the conceptual importance of whether inactivation of the MATNs decreases the latency to onset of the residual CRs (Kalmbach et al., 2009, 2010, 2011). To examine this, we used a one-way ANOVA comparing CR onset latency (using a $0.3-\mathrm{mm}$ amplitude threshold) during the postinfusion test phase (blocks 4-12) for muscimol, ACSF, and noninfusion sessions at two cannula depth ranges ( $>9 \mathrm{~mm}$ and $<9 \mathrm{~mm}$ ventral to brain surface) revealed no significant differences $\left(F_{(5,65)}=2.14, p=0.07\right)$. A one-way ANOVA assessing CR onset latency data during the preinfusion phase (blocks 1-3) among these conditions established no significant differences in performance during baseline training blocks $\left(F_{(5,65)}=1.88, p=0.11\right)$. When residual CRs were present during thalamic inactivation, the CRs remained well timed relative to control sessions, even for the most effective infusions (Fig. 5). Control session types ranged from 805 to 886 $\mathrm{ms}$ in average CR onset latency. The largest deviation from this range was the average CR onset latency of the $<9 \mathrm{~mm}$ muscimol group, which was more precisely timed than the other conditions (924 $\pm 7 \mathrm{~ms}$ ), possibly due to a larger proportion of CRs that were well timed but attenuated in amplitude. Combined, these data show that the effect of the inactivation of the MATN is to severely impair or block the expression of trace eyelid responses. The residual CRs seen during inactivation are smaller in amplitude but are properly timed.

\section{CS-driven inputs sufficient for trace conditioning: simulations}

Muscimol infusion into MATN could block the expression of trace eyelid responses through blocking CS-driven inputs to cerebellum (via pontine nuclei), blocking a pathway that is necessary for conveying auditory CS information to sites that generate persistent activity (which is then conveyed to cerebellum via pontine nuclei), or both. The delay-conditioning results presented here and by others indicate that the MATN are a necessary portion of the pathway providing auditory CS inputs to the cerebellum (Halverson et al., 2008). This focuses interpretation of the traceconditioning results, as follows: if blockade of the direct auditory CS pathway is sufficient to abolish the expression of trace re- 
sponses, then our results cannot address the role of MATN in generating task-related persistent activity. To this question, previous stimulation and cerebellum simulation results suggest that blocking only the pathway conveying CS-duration input is not sufficient to abolish trace responses, but instead alters CR timing by producing shorter latencies to onset.

For the simulation results, it is of concern that these key findings involve failures of the simulation: a failure to respond when persistent input is blocked and a breakdown in timing when the auditory CS pathway is blocked. These results support the parallel empirical observations only to the extent that they do not simply represent shortcomings of the simulation itself. Because recent advances in the simulations have improved response timing and the ability to respond at longer ISIs, we used the larger and more sophisticated current versions of the simulations with enhanced timing capabilities to test the predicted effects of blocking either the CS-conveying mossy fiber input or the persistent activityconveying mossy fiber inputs on the expression of well trained trace responses.

As in the previous work, we trained the simulations with separate mossy fiber inputs to mimic the temporal patterns of activity observed in tone CS-driven mossy fibers (500 ms) and in mossy fibers conveying persistent activity that extends beyond CS offset (1000 ms; Fig. 6A; Kalmbach et al., 2010). Training the simulation with 1000 trials using this compound mossy fiber input produced robust conditioned responding, with CR properties similar to trace eyelid CRs produced in rabbits. Over the final 100 trials of acquisition training, the CR likelihood was $85.2 \%$ and the mean CR latency to onset (using a $0.3-\mathrm{mm}$ amplitude inflection threshold) was $898 \pm 54 \mathrm{~ms}$; Figure $6 B$ ). Once the simulation was trained to this stable performance level, we first ran the following three 100-trial probe sessions: (1) only the CS-driven mossy fiber inputs were presented (Fig. 6C, top); (2) only the persistent-activity mossy fiber inputs were presented (Fig. 6C, middle); and (3) the normal compound inputs (both CS and persistent mossy fiber inputs) were presented (Fig. $6 C$, bottom). For these probes, if CS or persistent mossy fiber activity was elicited, it occurred in $100 \%$ of the population. Synaptic plasticity was disabled during these probe sessions to preclude any contributions from extinction. The results showed that both inputs were necessary for the simulation to express properly timed responses (90\% CRs; CR latency to onset, $895.2 \pm 60 \mathrm{~ms}$; CR amplitude, $4.2 \pm 1.5 \mathrm{~mm}$ ). CS-duration inputs alone failed to elicit CRs ( $0 \%$ CRs), while persistent-like inputs alone resulted in robust CRs (100\% CRs) of full amplitude $(4.5 \pm 0.6 \mathrm{~mm})$ but at abnormally short latencies to onset $(418 \pm 58 \mathrm{~ms})$. The onset latencies of these CRs were significantly shorter than those elicited by the normal, compound CS/persistent input probes $\left(t_{(188)}\right.$ $=54.89, p=1.15 \mathrm{e}-117$; Fig. 5, simulation CR latency data relative to in vivo behavioral data).

These initial simulation probe conditions tested the expected behavioral effects of complete inactivation of the CS or persistent pathways. A subset of muscimol infusions, however, resulted in partial effects, with residual CRs showing decreases in likelihood and amplitude, but with normal timing. Because these partial behavioral effects imply partial inactivation of relevant pathways, we also tested the simulations with incomplete inactivation of CS-duration and/or persistent-duration inputs (1) to determine whether the simulation results were unique to complete inactivation of inputs and (2) to test whether the simulations produced properly timed CRs, even when amplitude and likelihood displayed decreases.
To implement these tests, we presented 12 additional 100-trial probe sessions using various combinations of graded mossy fiber activation levels $(75 \%, 50 \%$, or $25 \%$ of mossy fibers active) in each of the two mossy fiber populations (CS and persistent). These probes tested one of four categories (detailed in Materials and Methods) based on whether one input population level or both CS- and persistent-duration mossy fiber input levels were simultaneously manipulated [Fig. 7, summary of descriptive results for each graded probe type (grayscale) relative to initial simulation conditions, black]. Results of the graded probe simulations showed that partial inactivation of required input pathways can produce decreases in CR likelihoods and amplitudes, while changes in CR timing occur only when the CS input is inhibited more than the persistent input. For graded CS inputs with persistent inputs fully intact, probes produced moderate decreases in CR likelihoods (56-63\% CRs), amplitudes (2.9-3.1 $\mathrm{mm}$ ), and CR onset latencies (progressive decrease from 908 to $728 \mathrm{~ms}$ as CS input levels decreased). In contrast, activation levels of $75 \%$ in both CS and persistent input populations, which also resulted in a moderate decrease in CR amplitude, showed well timed CR onset latencies (945 ms) and a larger decrease in CR likelihood (35\% CRs). As expected, performance levels during partial inactivation of persistent inputs (with CS input levels free to vary; $0-35 \% \mathrm{CRs)}$ were similar to in vivo performance levels during the most effective MATN inactivations $(>9 \mathrm{~mm})$. Together, the results of the graded probes support the general conclusion of our initial probe simulations and further indicate that graded CS inactivation alone is not sufficient to produce our partial effects in vivo.

Through implementing important simulation enhancements and novel probe conditions, the results corroborate and extend previous experimental and computational findings (Kalmbach et al., 2010) that blocking or omitting only the direct auditory CS input to the cerebellum is not sufficient to abolish trace eyelid CRs. These results also further support the notion that during trace eyelid conditioning the cerebellum learns to respond to the persistent input and uses the CS-duration input to learn to suppress CRs, thereby improving CR timing. This explains, in part, the observation that trace responses are better timed than delay responses at the same ISI (Kalmbach et al., 2009). Together, these results suggest that contralateral silencing of MATN is not abolishing the expression of trace CRs solely through blockade of the CS-duration input to the cerebellum. Instead, these results suggest the following two roles for MATN: (1) they provide the direct $\mathrm{CS}$ input to the cerebellum during both delay and trace eyelid conditioning; and (2) they are a necessary component of pathways conveying CS information to the brain regions that are generating the persistent activity that is necessary for trace eyelid conditioning.

\section{Discussion}

We have shown that unilateral inactivation of MATN reversibly blocks the expression of CRs of the contralateral eye in auditory trace and delay eyelid conditioning. The most effective placements were centered on MATN or within their ventral extent. Infusions that were more dorsal to MATN produced significantly smaller effects on CR expression. When muscimol infusions did not completely abolish CRs, the spared responses were lower in amplitude compared with control sessions, but their timing (expressed as latency to the criterion) was unchanged. The delayconditioning results parallel those of rodent studies showing that MATN inactivation blocks the lateralized, CS-driven input to the cerebellum (via the pontine nuclei) that is necessary for the ex- 
pression of CRs (Halverson and Freeman, 2006; Halverson et al., 2008). Such effects have been demonstrated to be modality specific, suggesting that these muscimol effects are unlikely to be caused by general disruptions to sensory or motor processing (Halverson and Freeman, 2006, 2010b). Current simulation results corroborate reports that blocking only the direct, CS-driven input to cerebellum is not sufficient to abolish trace CRs. The abolition of trace responses in the current inactivation experiment therefore suggests that the MATN are a necessary component of the pathway that conveys the persistent input signal to the cerebellum that is necessary for acquisition and expression of trace eyelid responses.

Previous studies have provided evidence for a central role of MATN in a number of other auditory-driven learning tasks, including pavlovian fear conditioning (LeDoux et al., 1984; Iwata et al., 1986; Edeline and Weinberger, 1992; McCabe et al., 1993; Maren et al., 2001), delay eyelid conditioning in rodents (Halverson and Freeman, 2006; Halverson et al., 2008), and differential conditioning paradigms (Ryugo and Weinberger, 1978; Jarrell et al., 1986; Poremba and Gabriel, 1997; Ferrara et al., 2017). The present pharmacological inactivation experiments extend the necessary role of the MATN to trace eyelid conditioning in rabbits. The conservation of the necessity of these nuclei across species and paradigms suggests a fundamental processing role during auditory learning (Halverson et al., 2015).

While infusion-based inactivation studies are limited in their ability to localize lesion sites precisely, we observed the most robust effects on trace $\mathrm{CR}$ expression with infusion cannula tips in the center and ventral-most regions of the MATN. Past work using ibotenic acid lesions, which creates a more precise lesion and spares fibers of passage, more clearly demarcated areas of MATN necessary for auditory-cued conditioning tasks (Jarrell et al., 1986; McCabe et al., 1993; Halverson and Freeman, 2006). Ibotenic acid lesion effects from the eyelid study ruled out the necessity of the dorsal and ventral divisions of medial geniculate and localized the auditory CS pathway to MATN (Halverson and Freeman, 2006). A heart rate variant of auditory delay conditioning also distinguished the necessity of the MATN from the dorsal division of the medial geniculate (Jarrell et al., 1987). Moreover, the extent of a brain lesion or inactivation typically affects the magnitude of the behavioral effect. Incomplete lesions of MATN or cannula sites $>0.5 \mathrm{~mm}$ from target in delay eyelidconditioning studies resulted in only partial impairment during CR acquisition and retention (Halverson et al., 2008). Not surprisingly, we found that cannula placements dorsal to the MATN led to partial behavioral effects, likely due to incomplete muscimol spread over the region of interest, which spans up to $3 \mathrm{~mm}$ in the anterior-posterior and dorsal-ventral planes in the rabbit (Girgis and Wang, 1981; de Venecia et al., 1995). Similar to the delay eyelid studies described above that were able to localize the effect to complete lesions of MATN, more accurately targeted placements led to complete abolishment of trace CRs. The abovecited literature supports the specificity of our delay effect to MATN. However, the lack of involvement of additional medial geniculate subregions, which are not required for delay conditioning, would need to be explicitly tested for trace conditioning, given that we cannot rule out the possible spread of muscimol to nuclei immediately adjacent to MATN.

The necessity of both the CS-duration and persistent inputs to the cerebellum in trace conditioning is central to the interpretation of the current results. A number of observations combine to support this notion. The use of mossy fiber stimulation as a CS during delay conditioning results in CR acquisition that is largely indistinguishable from that supported by tone CSs. In contrast, CS-duration mossy fiber stimulation does not support acquisition in trace conditioning using a $500 \mathrm{~ms}$ trace interval. However, combining this input with stimulation through a second mossy fiber electrode that persists through the trace interval is sufficient for the cerebellum to produce learned eyelid responses that are indistinguishable from normal trace eyelid CRs trained to a peripheral CS (Kalmbach et al., 2009, 2010). In the same well trained subjects, probe trials using only the CS-duration mossy fiber stimulation did not elicit CRs, whereas probes using only the persistent input elicited CRs with shorter than normal latencies to onset (Kalmbach et al., 2010). These data demonstrate the sufficiency and necessity of two distinct cerebellar inputs for the acquisition and normal expression of trace eyelid conditioning: a CS-duration input and a persistent input that extends into the stimulus-free interval.

Previous computer simulations of the cerebellum and those reported here have produced parallel results. Additionally, we have extended these experiments to test the behavioral effects of graded activation of CS- and persistent-duration mossy fiber populations, which are possible with partial inactivations. In general terms, these findings suggest that persistent input is required for cerebellar learning and that combined CS and persistent inputs improve timing-the cerebellum seemingly learns to suppress responding when both inputs are active and produce associative learned responses when only the persistent input is active (Kalmbach et al., 2011). Informed by these data, our current results are consistent with the hypothesis that the MATN are both a necessary portion of the direct auditory CS pathway to the cerebellum and a necessary portion of the auditory pathways that give rise to the persistent input required by the cerebellum to learn in trace conditioning. A key component of the above logic is that activating only the CS-conveying input fails to elicit CRs, which previous simulation results also supported. Further simulation tests with graded persistent mossy fiber inputs paired with CS-duration input (100\%) indicate severe CR performance decline even with $75 \%$ of persistent mossy fibers intact.

Previous simulations (Kalmbach et al., 2010) lacked recently discovered anatomical connections (Hull and Regehr, 2012; Houck and Person, 2015; Kim and Augustine, 2016) that are important for the timing and performance of eyelid conditioning and were also considerably smaller and less sophisticated than the current simulation. Their failure to elicit CRs during CS-only probes may have occurred because of the limitations of the simulation, rather than in a way that would inform mechanistic interpretations. This is especially pertinent given that two key ways in which the performance capabilities of the current simulations have been improved are greater precision in response timing and improved ability to learn and respond at longer ISIs. The enhanced ability of the current simulation to express CRs for a wider range of probe conditions, similar to rabbit data at longer ISIs, serves to increase the likelihood of CR expression on CSalone probes. In this way, our larger simulations offer a more stringent test of the idea that the persistent input is necessary for trace conditioning and that the CS-driven input helps to improve timing. The strong implication for our results is that the MATN are necessary for the arrival of the persistent input to the cerebellum. Based on these results we predict that MATN inactivation would abolish or attenuate task-related persistent activity in pons and upstream projection sources, such as medial prefrontal cortex (Takehara-Nishiuchi and McNaughton, 2008; Siegel et al., 2012) and auditory cortical regions (Knowlton et al., 1993; Huang et al., 2016; Sensory cortical involvement in trace condi- 
tioning using a different stimulus modality has also been reported: Galvez et al., 2007). Ongoing studies are addressing these hypotheses.

The goal of these inactivation and simulation experiments was to provide a foundation from which to map the pathways that are necessary for linking sensory responses to learned behavioral outputs during trace conditioning. The necessity of forebrain cortical structures for trace but not delay eyelid conditioning has been the basis for much of the interest in trace eyelid conditioning. This interest now extends to hypotheses centering on the sites and mechanisms generating the persistent signals that bridge the temporal gap between CS and US and thereby enable cerebellar plasticity and trace learning. Specifically, a robust understanding of persistent activity requires identifying where and how stimulus-duration neural responses are converted to persistent responses, and how these persistent responses are used by other brain regions. Delineating the specific CS pathway is key to a comprehensive theory of persistent activity and working memory and can shed light on the fundamental processing principles of forebrain structures.

\section{References}

Aitkin LM, Boyd J (1978) Acoustic input to the lateral pontine nuclei. Hear Res 1:67-77. CrossRef Medline

Boyd J, Aitkin L (1976) Responses of single units in the pontine nuclei of the cat to acoustic stimulation. Neurosci Lett 3:259-263. CrossRef Medline

Caballero-Bleda M, Fernandez B, Puelles L (1991) Acetylcholinesterase and $\mathrm{NADH}$-diaphorase chemoarchitectonic subdivisions in the rabbit medial geniculate body. J Chem Neuroanat 4:271-280. CrossRef Medline

Campolattaro MM, Halverson HE, Freeman JH (2007) Medial auditory thalamic stimulation as a conditioned stimulus for eyeblink conditioning in rats. Learn Mem 14:152-159. CrossRef Medline

Coesmans M, Weber JT, De Zeeuw CI, Hansel C (2004) Bidirectional parallel fiber plasticity in the cerebellum under climbing fiber control. Neuron 44:691-700. CrossRef Medline

Dembrow NC, Chitwood RA, Johnston D (2010) Projection-specific neuromodulation of medial prefrontal cortex neurons. J Neurosci 30:1692216937. CrossRef Medline

de Venecia RK, Smelser CB, Lossman SD, McMullen NT (1995) Complementary expression of parvalbumin and calbindin D-28k delineates subdivisions of the rabbit medial geniculate body. J Comp Neurol 359: 595-612. CrossRef Medline

Edeline JM, Weinberger NM (1992) Associative retuning in the thalamic source of input to the amygdala and auditory cortex: receptive field plasticity in the medial division of the medial geniculate body. Behav Neurosci 106:81-105. CrossRef Medline

Egorov AV, Hamam BN, Fransén E, Hasselmo ME, Alonso AA (2002) Graded persistent activity in entorhinal cortex neurons. Nature 420:173178. CrossRef Medline

Ferrara NC, Cullen PK, Pullins SP, Rotondo EK, Helmstetter FJ (2017) Input from the medial geniculate nucleus modulates amygdala encoding of fear memory discrimination. Learn Mem 24:414-421. CrossRef Medline

Freeman JH Jr, Muckler AS (2003) Developmental changes in eyeblink conditioning and neuronal activity in the pontine nuclei. Learn Mem 10:337345. CrossRef Medline

Funahashi S, Bruce CJ, Goldman-Rakic PS (1989) Mnemonic coding of visual space in the monkey's dorsolateral prefrontal cortex. J Neurophysiol 61:331-349. CrossRef Medline

Fuster JM, Alexander GE (1971) Neuron activity related to short-term memory. Science 173:652-654. CrossRef Medline

Galvez R, Weible AP, Disterhoft JF (2007) Cortical barrel lesions impair whisker-CS trace eyeblink conditioning. Learn Mem 14:94-100. CrossRef Medline

Gilmartin MR, McEchron MD (2005) Single neurons in the medial prefrontal cortex of the rat exhibit tonic and phasic coding during trace fear conditioning. Behav Neurosci 119:1496-1510. CrossRef Medline

Girgis M, Wang S-C (1981) A new stereotaxic atlas of the rabbit brain. St. Louis, MO: Warren H. Green.

Guo ZV, Inagaki H, Daie K, Druckmann S, Gerfen CR, Svoboda K (2017)
Maintenance of persistent activity in a frontal thalamocortical loop. Nature 545:181-186. CrossRef Medline

Halverson HE, Freeman JH (2006) Medial auditory thalamic nuclei are necessary for eyeblink conditioning. Behav Neurosci 120:880-887. CrossRef Medline

Halverson HE, Freeman JH (2010a) Medial auditory thalamic input to the lateral pontine nuclei is necessary for auditory eyeblink conditioning. Neurobiol Learn Mem 93:92-98. CrossRef Medline

Halverson HE, Freeman JH (2010b) Ventral lateral geniculate input to the medial pons is necessary for visual eyeblink conditioning in rats. Learn Mem 17:80-85. CrossRef Medline

Halverson HE, Poremba A, Freeman JH (2008) Medial auditory thalamus inactivation prevents acquisition and retention of eyeblink conditioning. Learn Mem 15:532-538. CrossRef Medline

Halverson HE, Poremba A, Freeman JH (2015) Medial auditory thalamus is necessary for acquisition and retention of eyeblink conditioning to cochlear nucleus stimulation. Learn Mem 22:258-266. CrossRef Medline

Hattori S, Yoon T, Disterhoft JF, Weiss C (2014) Functional reorganization of a prefrontal cortical network mediating consolidation of trace eyeblink conditioning. J Neurosci 34:1432-1445. CrossRef Medline

Hausknecht M, Li WK, Mauk M, Stone P (2017) Machine learning capabilities of a simulated cerebellum. IEEE Trans Neural Netw Learn Syst 28: 510-522. CrossRef Medline

Houck BD, Person AL (2015) Cerebellar premotor output neurons collateralize to innervate the cerebellar cortex. J Comp Neurol 523:2254-2271. CrossRef Medline

Huang Y, Matysiak A, Heil P, König R, Brosch M (2016) Persistent neural activity in auditory cortex is related to auditory working memory in humans and nonhuman primates. Elife 5:e15441. CrossRef Medline

Hull C, Regehr WG (2012) Identification of an inhibitory circuit that regulates cerebellar Golgi cell activity. Neuron 73:149-158. CrossRef Medline

Ito M, Kano M (1982) Long-lasting depression of parallel fiber-Purkinje cell transmission induced by conjunctive stimulation of parallel fibers and climbing fibers in the cerebellar cortex. Neurosci Lett 33:253-258. Medline

Iwata J, LeDoux JE, Meeley MP, Arneric S, Reis DJ (1986) Intrinsic neurons in the amygdaloid field projected to by the medial geniculate body mediate emotional responses conditioned to acoustic stimuli. Brain Res 383: 195-214. CrossRef Medline

Jarrell TW, Romanski LM, Gentile CG, McCabe PM, Schneiderman N (1986) Ibotenic acid lesions in the medial geniculate region prevent the acquisition of differential pavlovian conditioning of bradycardia to acoustic stimuli in rabbits. Brain Res 382:199-203. CrossRef Medline

Jarrell TW, Gentile CG, Romanski LM, McCabe PM, Schneiderman N (1987) Involvement of cortical and thalamic auditory regions in retention of differential bradycardia conditioning to acoustic conditioned stimuli in rabbits. Brain Res 412:285-294. CrossRef Medline

Kalmbach BE, Ohyama T, Kreider JC, Riusech F, Mauk MD (2009) Interactions between prefrontal cortex and cerebellum revealed by trace eyelid conditioning. Learn Mem 16:86-95. CrossRef Medline

Kalmbach BE, Ohyama T, Mauk MD (2010) Temporal patterns of inputs to cerebellum necessary and sufficient for trace eyelid conditioning. J Neurophysiol 104:627-640. CrossRef Medline

Kalmbach BE, Voicu H, Ohyama T, Mauk MD (2011) A subtraction mechanism of temporal coding in cerebellar cortex. J Neurosci 31:2025-2034. CrossRef Medline

Kawamura K (1975) The pontine projection from the inferior colliculus in the cat. an experimental anatomical study. Brain Res 95:309-322. CrossRef Medline

Kim J, Augustine GJ (2016) A novel cerebellar molecular layer interneuron inhibited by Purkinje cell feedback. Soc Neurosci Abstr 42:719.14.

Knowlton BJ, Thompson JK, Thompson RF (1993) Projections from the auditory cortex to the pontine nuclei in the rabbit. Behav Brain Res 56: 23-30. CrossRef Medline

LeDoux JE, Sakaguchi A, Reis DJ (1984) Subcortical efferent projections of the medial geniculate nucleus mediate emotional responses conditioned to acoustic stimuli. J Neurosci 4:683-698. CrossRef Medline

Lev-Ram V, Wong ST, Storm DR, Tsien RY (2002) A new form of cerebellar long-term potentiation is postsynaptic and depends on nitric oxide but not cAMP. Proc Natl Acad Sci U S A 99:8389-8393. CrossRef Medline

Lev-Ram V, Mehta SB, Kleinfeld D, Tsien RY (2003) Reversing cerebellar 
long-term depression. Proc Natl Acad Sci U S A 100:15989-15993. CrossRef Medline

Malmierca MS, Merchán MA, Henkel CK, Oliver DL (2002) Direct projections from cochlear nuclear complex to auditory thalamus in the rat. J Neurosci 22:10891-10897. CrossRef Medline

Maren S, Yap SA, Goosens KA (2001) The amygdala is essential for the development of neuronal plasticity in the medial geniculate nucleus during auditory fear conditioning in rats. J Neurosci 21:RC135. Medline

Mauk MD, Donegan NH (1997) A model of pavlovian eyelid conditioning based on the synaptic organization of the cerebellum. Learn Mem 4:130158. CrossRef Medline

McCabe PM, McEchron MD, Green EJ, Schneiderman N (1993) Electrolytic and ibotenic acid lesions of the medial subnucleus of the medial geniculate prevent the acquisition of classically conditioned heart rate to a single acoustic stimulus in rabbits. Brain Res 619:291-298. CrossRef Medline

Medina JF, Mauk MD (1999) Simulations of cerebellar motor learning: computational analysis of plasticity at the mossy fiber to deep nucleus synapse. J Neurosci 19:7140-7151. CrossRef Medline

Medina JF, Garcia KS, Nores WL, Taylor NM, Mauk MD (2000) Timing mechanisms in the cerebellum: testing predictions of a large-scale computer simulation. J Neurosci 20:5516-5525. CrossRef Medline

Navaroli VL, Zhao Y, Boguszewski P, Brown TH (2012) Muscarinic receptor activation enables persistent firing in pyramidal neurons from superficial layers of dorsal perirhinal cortex. Hippocampus 22:1392-1404. CrossRef Medline

O’Connor KN, Allison TL, Rosenfield ME, Moore JW (1997) Neural activity in the medial geniculate nucleus during auditory trace conditioning. Exp Brain Res 113:534-556. CrossRef Medline

Poremba A, Gabriel M (1997) Medial geniculate lesions block amygdalar and cingulothalamic learning-related neuronal activity. J Neurosci 17: 8645-8655. CrossRef Medline

Pugh JR, Raman IM (2006) Potentiation of mossy fiber EPSCs in the cerebellar nuclei by NMDA receptor activation followed by postinhibitory rebound current. Neuron 51:113-123. CrossRef Medline

Pugh JR, Raman IM (2008) Mechanisms of potentiation of mossy fiber
EPSCs in the cerebellar nuclei by coincident synaptic excitation and inhibition. J Neurosci 28:10549-10560. CrossRef Medline

Raymond JL, Lisberger SG (1998) Neural learning rules for the vestibuloocular reflex. J Neurosci 18:9112-9129. CrossRef Medline

Ryugo DK, Weinberger NM (1978) Differential plasticity of morphologically distinct neuron populations in the medial geniculate body of the cat during classical conditioning. Behav Biol 22:275-301. CrossRef Medline

Safo P, Regehr WG (2008) Timing dependence of the induction of cerebellar LTD. Neuropharmacology 54:213-218. CrossRef Medline

Sears LL, Steinmetz JE (1991) Dorsal accessory inferior olive activity diminishes during acquisition of the rabbit classically conditioned eyelid response. Brain Res 545:114-122. CrossRef Medline

Siegel JJ, Kalmbach B, Chitwood RA, Mauk MD (2012) Persistent activity in a cortical-to-subcortical circuit: bridging the temporal gap in trace eyelid conditioning. J Neurophysiol 107:50-64. CrossRef Medline

Steinmetz JE, Sengelaub DR (1992) Possible conditioned stimulus pathway for classical eyelid conditioning in rabbits. I. anatomical evidence for direct projections from the pontine nuclei to the cerebellar interpositus nucleus. Behav Neural Biol 57:103-115. CrossRef Medline

Suzuki WA, Miller EK, Desimone R (1997) Object and place memory in the macaque entorhinal cortex. J Neurophysiol 78:1062-1081. CrossRef Medline

Tahvildari B, Fransén E, Alonso AA, Hasselmo ME (2007) Switching between "on" and "off" states of persistent activity in lateral entorhinal layer III neurons. Hippocampus 17:257-263. CrossRef Medline

Takehara-Nishiuchi K, McNaughton BL (2008) Spontaneous changes of neocortical code for associative memory during consolidation. Science 322:960-963. CrossRef Medline

Winer JA, Larue DT, Huang CL (1999) Two systems of giant axon terminals in the cat medial geniculate body: convergence of cortical and GABAergic inputs. J Comp Neurol 413:181-197. CrossRef Medline

Winer JA, Diehl JJ, Larue DT (2001) Projections of auditory cortex to the medial geniculate body of the cat. J Comp Neurol 430:27-55. CrossRef Medline

Zhou YD, Fuster JM (1996) Mnemonic neuronal activity in somatosensory cortex. Proc Natl Acad Sci U S A 93:10533-10537. CrossRef Medline 